\title{
A comprehensive overview of substrate specificity of glycoside hydrolases and transporters in the small intestine
}

\section{"A gut feeling"}

\author{
Hidde Elferink ${ }^{1}$. Jeroen P. J. Bruekers ${ }^{1}$ - Gerrit H. Veeneman ${ }^{2}$. Thomas J. Boltje ${ }^{1}$ (])
}

Received: 10 April 2020 / Revised: 21 May 2020 / Accepted: 25 May 2020 / Published online: 6 June 2020

(c) The Author(s) 2020

\begin{abstract}
The human body is able to process and transport a complex variety of carbohydrates, unlocking their nutritional value as energy source or as important building block. The endogenous glycosyl hydrolases (glycosidases) and glycosyl transporter proteins located in the enterocytes of the small intestine play a crucial role in this process and digest and/or transport nutritional sugars based on their structural features. It is for these reasons that glycosidases and glycosyl transporters are interesting therapeutic targets to combat sugar related diseases (such as diabetes) or to improve drug delivery. In this review we provide a detailed overview focused on the molecular structure of the substrates involved as a solid base to start from and to fuel research in the area of therapeutics and diagnostics.
\end{abstract}

In most diets, carbohydrates constitute a major source of energy in the form of digestible oligo- and disaccharides. For example, amylose ( $\alpha$-1,4-linked glucose) and amylopectin ( $\alpha-1,6$ branched $\alpha$-1,4-linked glucose) are components of starches and an important source of glucose. Disaccharides such as sucrose $(\alpha$-Glc- $\rightarrow 2-\beta$-Fruc), lactose $(\beta$-Gal- $1 \rightarrow 4-$ Glc $)$ and trehalose $(\alpha-$ Glc- $1 \rightarrow 1-\alpha$-Glc $)$ are precursors for fructose, galactose and glucose, respectively. To unlock the nutritional value of these molecules, the body expresses enzymes to hydrolyze the oligo- and disaccharides into their respective monosaccharide constituents followed by uptake via a series of monosaccharide transporters [1].

Upstream of intestinal digestion, large $\alpha$-linked polysaccharides such as amylose are degraded to disaccharides (e.g. maltose) and oligosaccharides by salivary- and pancreatic amylase [2]. In addition, a small amount is hydrolyzed in the stomach [3]. As these processes upstream of the small intestine produce negligible quantities of transportable sugars, they are beyond the scope of this review. The bulk of

Thomas J. Boltje

t.boltje@ru.nl

1 Institute for Molecules and Materials, Radboud University, Heyendaalseweg 135, 6525 Nijmegen, The Netherlands

2 PharmaCytics B.V., Noviotech Campus, Nijmegen, The Netherlands oligo- and disaccharide digestion and uptake occurs in the small intestine by the action of membrane bound glycosyl hydrolases present in the brush border of the jejunum (Fig. 1). The breakdown of starch oligosaccharides is carried out by enzymes capable of cleaving the $\alpha-1,6-$ Glc and $\alpha$-1,4-Glc linkages such as the maltase-glucoamylase complex (MGAM) and sucrase isomaltase (SI). In addition, SI is also capable of cleaving sucrose into glucose and fructose. Lactose is converted by lactase-phlorizin hydrolase (LPH) yielding galactose and glucose. Trehalose, a disaccharides found in mushrooms, can be cleaved by trehalase (TREH) into two molecules of glucose. In addition to membrane bound glycosyl hydrolases, enterocytes also express intracellular human cytosolic $\beta$-glucosidase (hCBG), a broad specificity $\beta$-glycosidase enzyme.

The monosaccharides produced by glycosylhydrolases in the small intestine traverse the enterocytes lining the jejunum with the assistance of a number of monosaccharides transporters. Glucose and galactose are mainly taken up by SGLT1, a symport transporter of these monosaccharides and two sodium ions. Fructose is passively transported independent of sodium via facilitated transport by the action of GLUT5. SGLT1 and GLUT5 represent the major tools for enterocytes to enable monosaccharide uptake from the apical side. Subsequent basolateral excretion of monosaccharides into the bloodstream is facilitated by GLUT2. 


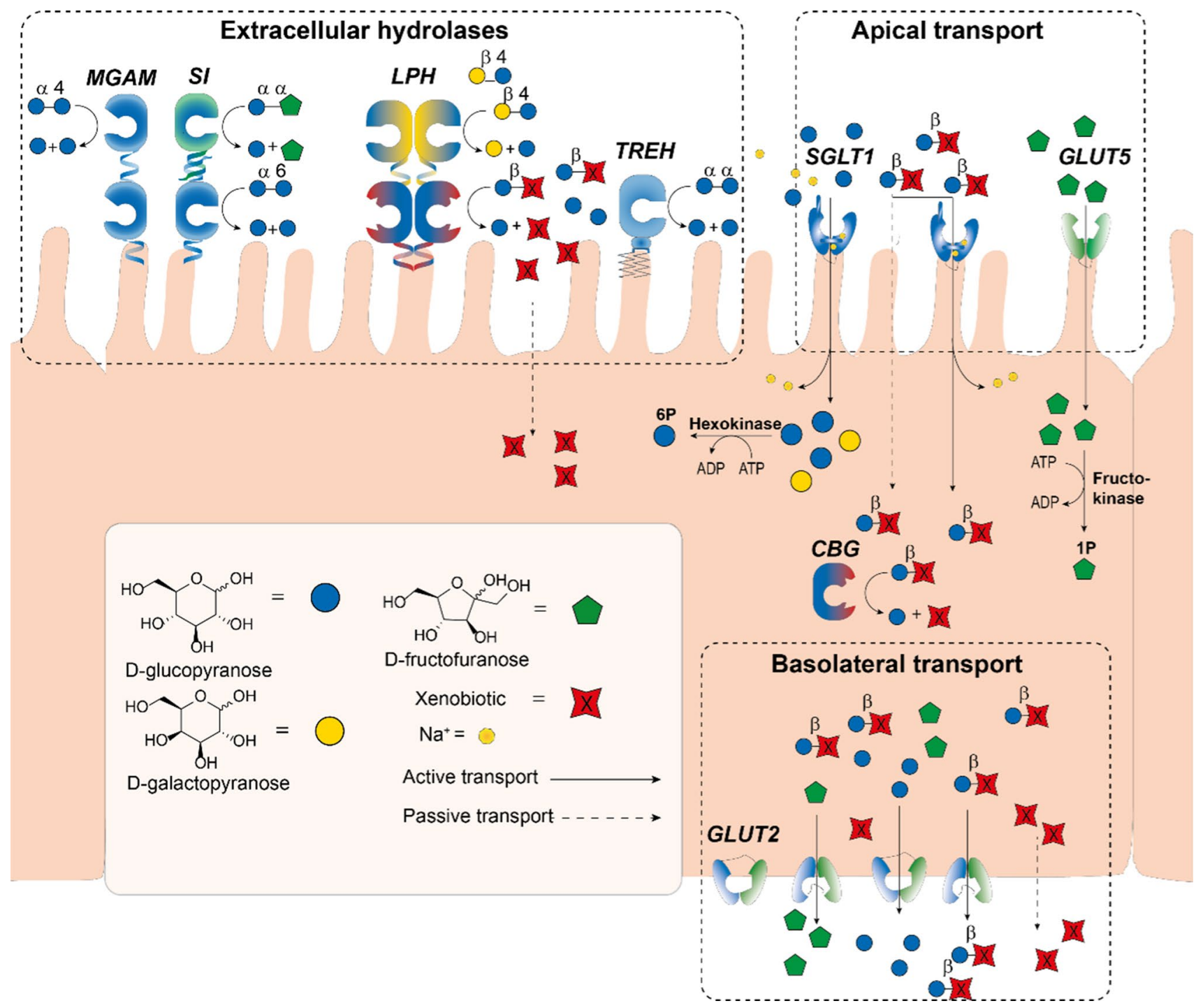

Fig. 1 Schematic overview of carbohydrate hydrolysis and transport in the enterocytes of the small intestine. Dietary saccharides and digested to produce monosaccharides that enter the enterocytes at the apical side of the enterocyte (top face) and are released at the baso-

The hydrolysis and uptake of carbohydrates is adaptable and responds to changes in the need for nutrients and their availability [4]. For example, increased glucose absorption is observed during pregnancy and lactation [5] or after surgical resection of the intestine [6]. The importance of a healthy interplay between intestinal glycosyl hydrolase activity and monosaccharide transport is further illustrated by diseases resulting from the altered activity of intestinal hydrolases and transporters. The most common disorder in this respect is lactose intolerance, a drop in lactase activity causing a build-up of lactose [7]. High lactose levels lead to the retention of water in the lumen resulting in diarrhea and other discomforts. lateral side. MGAM (maltase glucoamylase), SI (sucrase isomaltase), LPH (lactase phlorizin hydrolase), TREH (trehalose), CBG (cytosolic $\beta$-glucosidase), SGLT1 (sodium dependent glucose transporter 1), GLUT5 (glucose transporter 5), GLUT2 (glucose transporter 2)

Hence, the processing and uptake of dietary carbohydrates represents an important mechanism to take up energy and is crucial in health and disease. The observation that glycosylated flavonoids are better taken up compared to their non-glycosylated variants indicates that glycoconjugation and related hydrolysis and transport mechanisms may be exploited for improving oral drug uptake. Furthermore, modulating carbohydrate processing and uptake is an important therapeutic avenue to treat diabetes. In this review, we aim to summarize the current state of knowledge regarding the hydrolysis of oligo- and disaccharides and transport of the resulting monosaccharides at the molecular level. To this end, we will discuss the structure of the hydrolases and transporters involved as well as the scope of modifications 
of the monosaccharides that are tolerated. This information will be crucial to advance therapeutic and diagnostic efforts directed at the intestinal carbohydrate metabolism.

\section{General introduction}

\section{Glycosidase activity in the small intestinal brush border}

See Table 1.

\section{Glycosyl hydrolases in the small intestine}

The small intestinal brush border membrane and the cytosol of the enterocytes, contain glycosidases capable of hydrolyzing various ingested saccharides converting non-absorbable di- and oligosaccharides into nutritional monosaccharides [19]. The five endogenous glycosidases (or glycosyl hydrolases) involved in this process are MGAM, SI, LPH, TREH and CBG (Fig. 1). The glycosidases are part of a family of enzymes that catalyze the hydrolysis of the glycosidic linkage of (oligo)-saccharides or the glycosidic linkage between a carbohydrate (glycone) and a non-carbohydrate moiety (aglycone) [20]. The hydrolysis of the glycosidic bond is catalyzed by the carboxylic acid moieties of two amino acid residues of the enzyme: a general acid (proton donor) and a nucleophile/base. Depending on the arrangement of these groups hydrolysis of the glycosidic bond occurs with retention or inversion of the anomeric configuration [21-23]. MGAM and SI hydrolyze $\alpha$-glucosides with retention of configuration (Fig. 2a) and LPH and CBG hydrolyze $\beta$-glycosides with retention of configuration (Fig. 2b). In contrast, TREH digests $\alpha, \alpha$-trehalose with inversion of anomeric stereochemistry (Fig. 2c). The endogenous glycosidases are differentially expressed over the length of the small intestine. For example, MGAM is increasingly expressed along the intestine with the highest level in the distal ileum [24]. SI and LPH are mostly expressed in the jejunum with lower expression levels towards the proximal and distal ends of the intestine, whereas the spatial expression of TREH has not been reported yet [24]. Glycosidase deficiency leads to the inability to digest certain sugars causing symptoms such as chronic diarrhoea and malabsorption. The pathology or these deficiencies will be discussed briefly in every section.

A classification has been made into glycosyl hydrolase (GH) families (145 families to date) depending on the amino acid sequence similarities and these can be further classified into groups (reported as clans) by similarities in folds and catalytic mechanism (see the Carbohydrate Active enZYme or CAZY data set https://www.cazy.org) [20, 22]. In addition, in this review the sub-site nomenclature proposed by
Davies et al. for glycosyl hydrolase binding sites is adopted, where $n$ represents the reducing end of the carbohydrate chain, $-n$ represents the non-reducing end and cleavage occurs between the -1 and +1 binding sites [28].

\section{Maltase-glucoamylase as intestinal glycosidase}

The maltase-glucoamylase (MGAM, EC 3.2.1.20/3) complex accounts for all small intestinal glucoamylase activity, $20 \%$ of the maltase activity and a lesser amount of the isomaltase activity [29]. MGAM is expressed in the small intestinal brush border, representing about $2 \%$ of the brush border membrane proteins. In addition to the small intestine, MGAM is present in the renal tubular brush border membrane (Table 1). It is comprised of two subunits: the $N$-terminal subunit which hydrolyzes maltose (referred to as maltase) and the $C$-terminal subunit, that is able to hydrolyse longer oligomaltose substrates (als known as glucoamylase). It should be noted that although MGAM has a high activity for starch related oligomaltoses, at mealtime concentrations it experiences substrate inhibition. Instead, studies have shown that at high oligomaltose concentration sucroseisomaltase contributes to most of the $\alpha$-glycosidase activity [30]. MGAM deficiency disease in infant children leads to the inability to digest short chain oligomaltoses and results in chronic diarrhoea but not necessarily in malabsorption. The symptoms can be treated by avoiding starch and starchcontaining products in the diet [31]. Though the exact origin of MGAM deficiency remains unclear studies have shown it is likely not genetic [32]. Specific information about folds/ domains and the crystal structure ( $N$-terminal 3L4X [33], 2QMJ [34] and $C$-Terminal 3TON [8] and 3TOP [8]) can be found in studies by Rose and co-workers [34] and Ren et al. [8]. Various splice forms of ctMGAM exist in mammals and can be used for hydrolysis studies. The splice forms N2 and N20 from mice are often used as a model for human MGAM (hMGAM) as they have a $80 \%$ sequence identity [35]. Critically, the affinity of substrates tested may differ from the hMGAM.

The wild-type enzyme has a preference for $\alpha-1,4$ substituted oligo-glucosides (oligomaltose) and can hydrolyze increasing lengths up to glucohexaose efficiently. The regiochemistry is important as $\alpha$-1,6-glucosidic bonds are hydrolysed at only $2 \%$ of the rate of $\alpha-1,4$-glucosidic linkages. In addition, there is some $\alpha-1,2$ - and $\alpha-1,3$-glycosidase activity present whilst sucrose $(\alpha$-D-glucopyranosyl- $(1 \rightarrow 2)-\beta$-Dfructofuranoside) and $\beta-1,4$ and $\beta-1,6$ glucosidic linkages are not hydrolysed $[29,37-39]$. The substrate affinity and related activity of MGAM is summarized in Fig. 3. Data from the research groups of Hamaker [36] and Shen [8] are used for comparison. The group of Shen was first to report the crystal structure and substrate specificity for the human ctMGAM and compared this to recombinant human 
Table 1 Overview of human glycosidases and monosaccharide transporters and in the small intestine

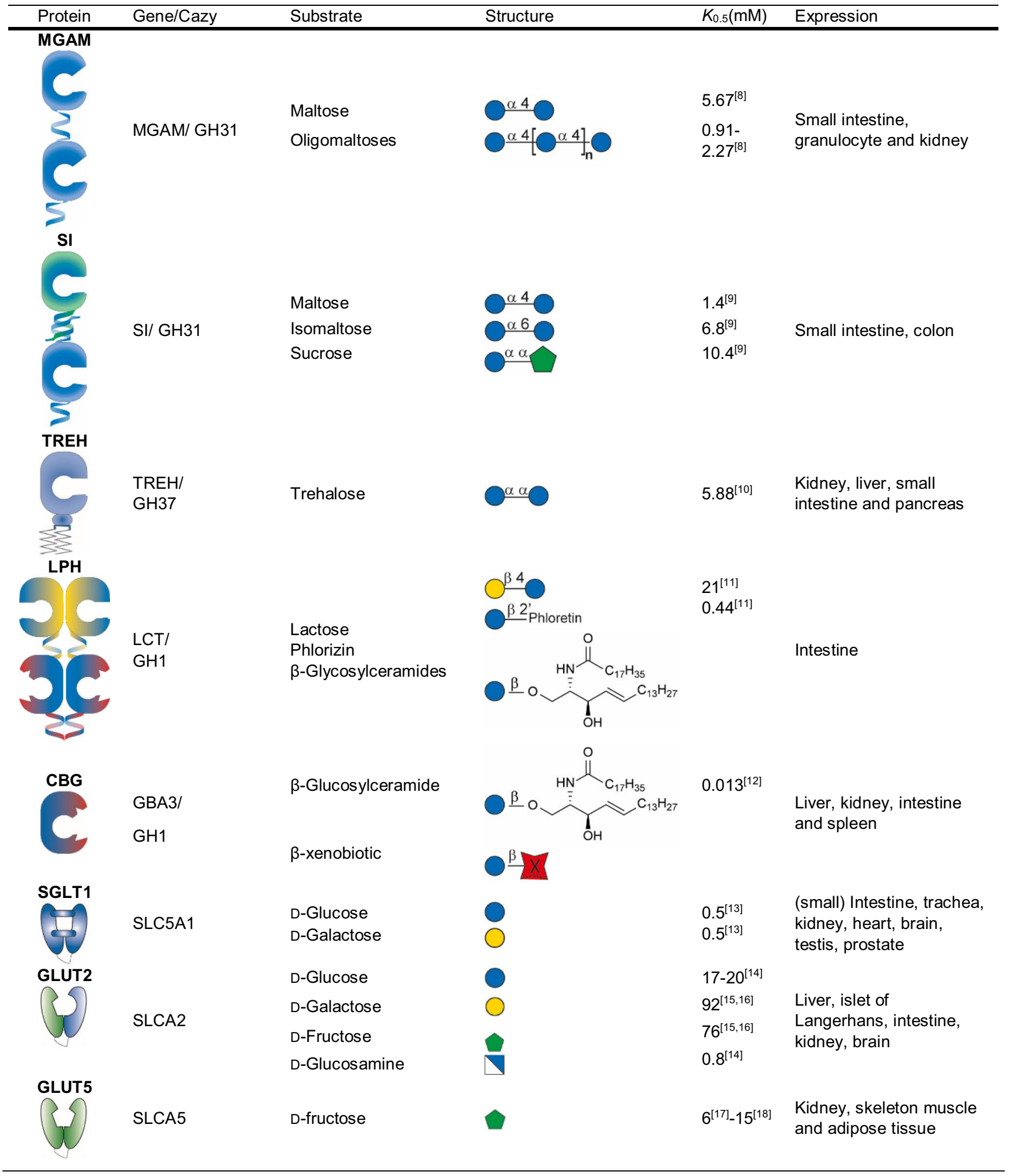

ntMGAM (Fig. 3a). The trends observed in substrate affinity of the $C$-terminal subunit clearly indicate the preference for longer chain maltose oligosaccharides with increasing affinity up to maltopentaose (Fig. 3a, n=3). Critically, the crystal structure showed that the ctMGAM had additional + 2 and +3 binding subsites which may explain the preference of ctMGAM for long chain sugars. In contrast, the ntMGAM subunit shows a preference for shorter oligosaccharides. The 
(a)

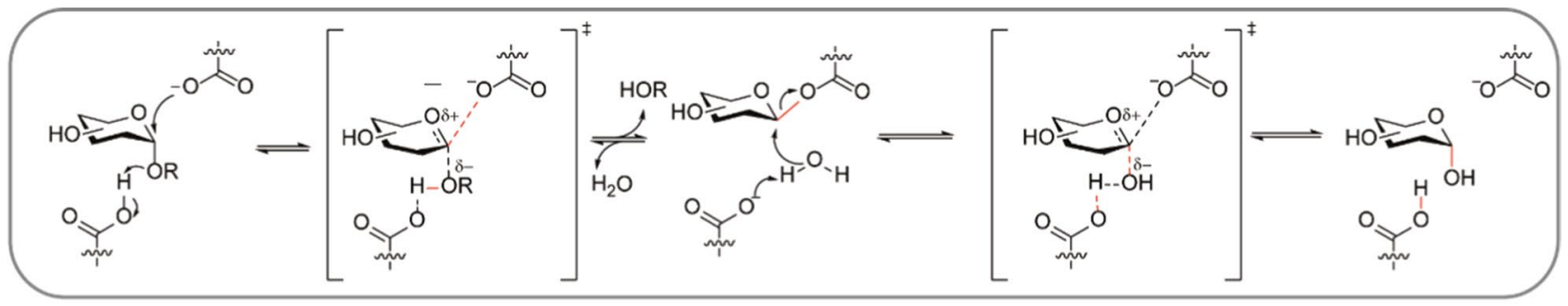

(b)

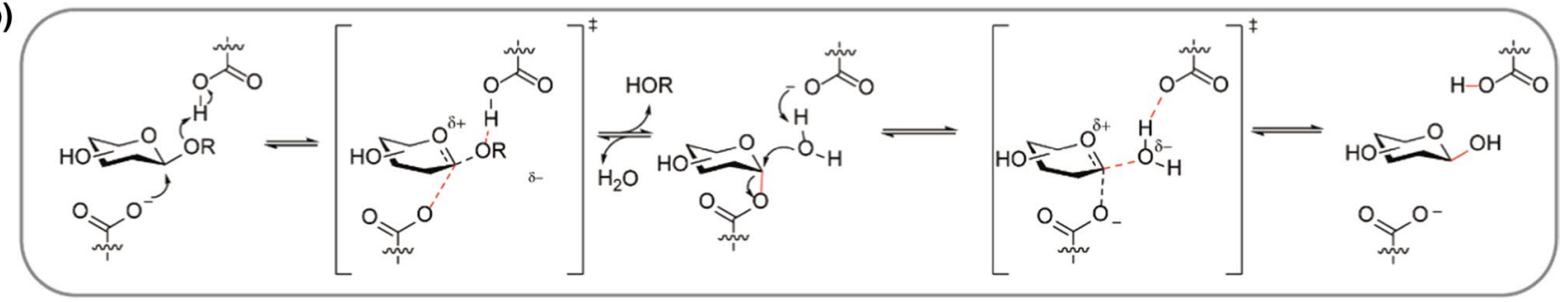

(c)

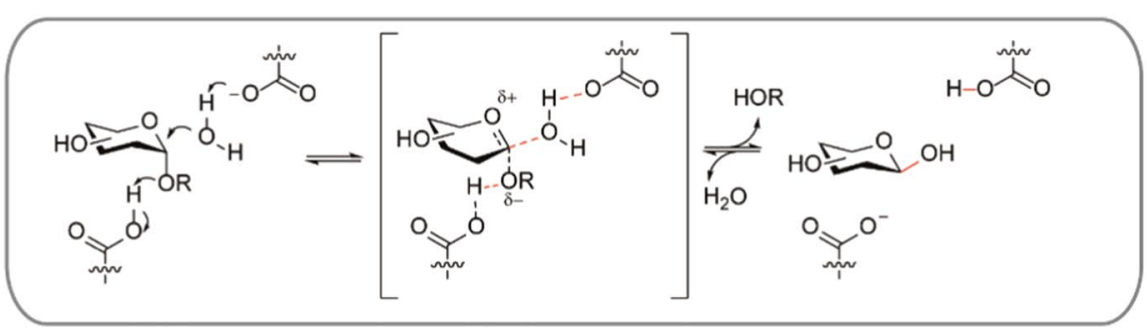

Fig. 2 Overview of Koshland's mechanism of glycoside hydrolysis in human intestinal glycosidases. a Retaining mechanism for $\alpha$-glucosidases SI and MGAM [22, 25]. b Retaining mechanism of
CBG and LPH in the hydrolysis of $\beta$-conjugated glycosides [22, 23, $25,26]$. c Inverting mechanism of the $\alpha$-glycosidase TREH [22, 25, 27]. Lines in red indicate the formation of new bonds activity towards disaccharides was studied on $C$-terminal remMGAM and $N$-terminal re-hMGAM by Hamaker and coworkers (Fig. 3b, c). Remarkably, nigerose and kojibiose were accepted in both subunits as substrates whereas no hydrolytic activity towards trehalose was observed. In addition, unexpected sucrase activity was found in the recombinant mouse ctMGAM used. Though interesting, the contribution to total sucrase activity is expected to be marginal since the amount of MGAM is forty times lower than SI in the small intestine. These important studies performed have fuelled numerous related research towards inhibitors of the MGAM complex (see Fig. 16, acarbose). Though MGAM is interesting as drug target against diabetes 2 and obesity, an elaborate discussion about inhibitory activities is beyond the scope of this review.

\section{Sucrase-isomaltase as intestinal glycosidase}

Sucrase isomaltase (SI, EC 3.2.1.48) accounts for approximately $80 \%$ of the overall intestinal maltase activity and almost all sucrase activity present in the intestine [40]. SI is one of the major proteins in the small intestinal brush border membrane in terms of abundance, making up about $8-10 \%$ of the proteins expressed [41]. Though abundantly present in mammals, SI is not significantly expressed until the weaning period after which expression levels stabilize during adult life [19]. The protein consists similar to MGAM of two catalytic subunits: the $C$-terminal subunit (sucrase) that hydrolyses sucrose (also known as saccharose or $\alpha$-Dglucopyranosyl-( $1 \rightarrow 2)-\beta$-D-fructofuranoside) to D-glucose and D-fructose. The D-glucose part of the molecule acts as glycon in this reaction. The $N$-terminal subunit (isomaltase) is mainly involved in the hydrolysis of isomaltose ( $\alpha$-Dglucopyranosyl-( $1 \rightarrow 6)-\alpha$-D-glucopyranoside) into two $\alpha$-D-glucose molecules. Both subunits of SI hydrolyse the substrates via a retaining mechanism (Fig. 2a). In contrast to MGAM, the subunits of SI are connected via a non-covalent interaction which is a result of the proteolytic cleavage of the pro-protein in situ [42]. SI also differs from MGAM as it has a low activity towards oligosaccharides [19, 29]. Interestingly, Naim and coworkers showed by selectively mutating and studying the separate catalytic sites that the sum of maltase activities of the individual subunits is higher than the maltase activity of the wild type enzyme. The glucose produced is able to inhibit SI activity both competitively, at the active site, and uncompetitively, via allosteric interactions [43]. The inhibitory effect observed is analogous to the effect observed in MGAM and is likely a regulatory mechanism to prevent excess glucose release in the small intestine. Congenital SI-deficiency (CSID) is an autosomal recessive 


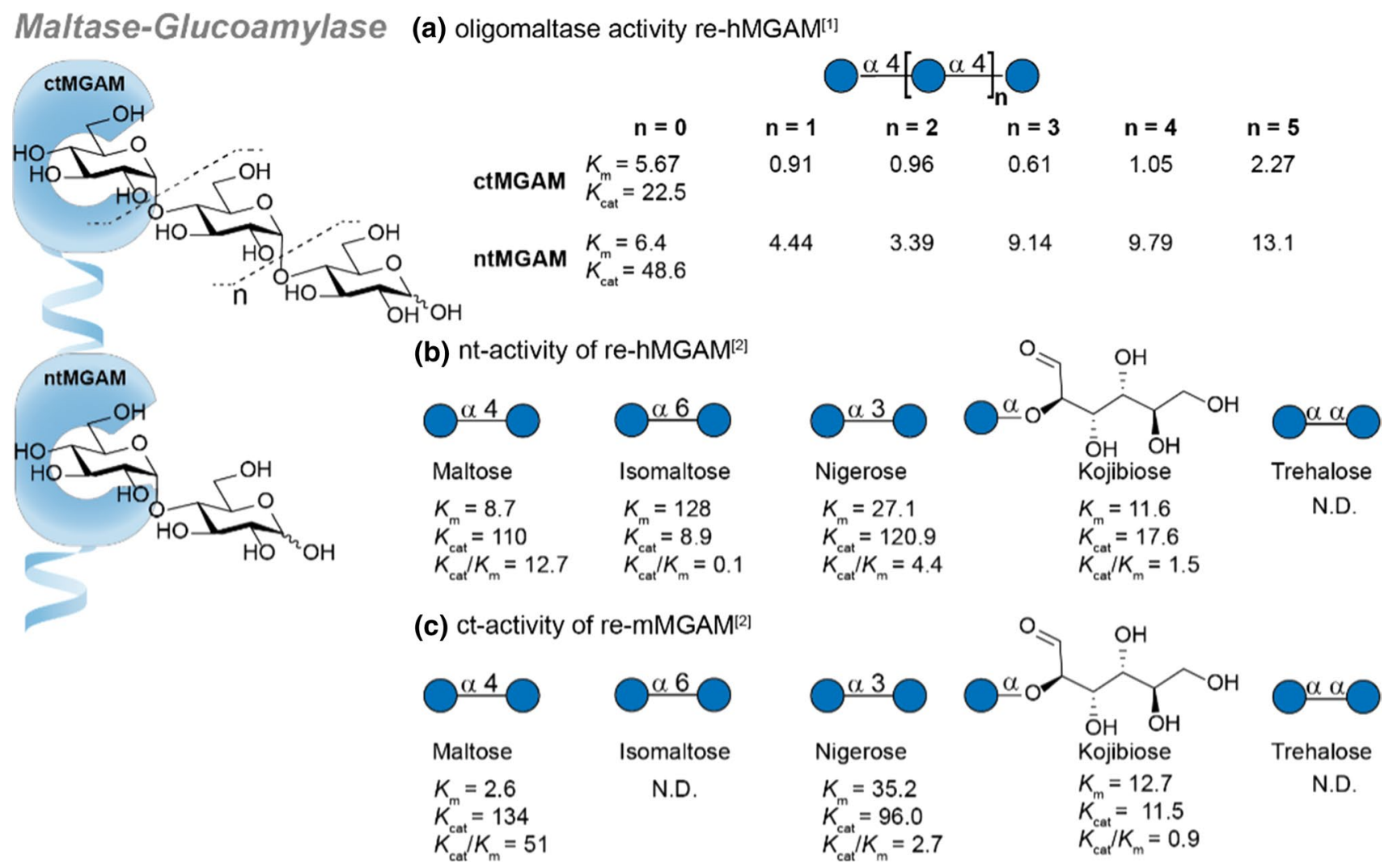

Fig. 3 Overview of the MGAM substrate affinity. a Substrate affinity of recombinant human MGAM $C$-terminal (ctMGAM) and $N$-terminal (ntMGAM) subunits towards oligomaltoses. b Overview of the nt-activity of re-hMGAM towards disaccharides. c Summarizes

disease that stems from mutations in the SI-complex. CSID leads to a total absence of sucrase activity whereas the isomaltase activity varies from low to normal depending on the phenotype [44]. Symptoms are vomiting, diarrhea and can in extremes cases lead to dehydration, developmental retardation and muscular hypothonia after sugar ingestion. Treatment in these cases is a lifelong sucrose restriction. For a detailed overview of CSID we refer to a review by Naim et al. [45]. Although the crystal structure of sucrase has not been obtained yet, the isomaltase-subunit of SI (3LPP) [34] has been crystallized. For structural comparison, Gericke et al.[43] modelled the sucrase sub-unit and compared it to the aforementioned crystal structure of isomaltase. The comparison showed, the active sites are likely to be very similar although ultimately a crystal structure of ctSI is needed to confirm this.

Figure 4a shows the combined activity of both subunits of wild-type hSI. As previously mentioned, the sucrase subunit contains practically all sucrase activity present in the small intestine. In addition, hSI can hydrolyze both $\alpha$-substituted gluco-type disaccharides maltose and isomaltose with a comparable $V_{\max }$, though maltose has a lower $K_{\mathrm{m}}$. Specific identical activity trend for recombinant mouse $C$-terminal MGAM (re-mMGAM). $K_{\mathrm{m}}(\mathrm{mM})$ and $K_{\text {cat }}$ in $\left(\mathrm{s}^{-1}\right)$. References used: ref 1 [8], ref 2 [36]

activity of both subunits was determined by recombinant expression of the $N$-terminus based on human cDNA (rehSI, Fig. 4b) and the $C$-terminus based on mouse cDNA (re-mSI, Fig. 4c). Interestingly, both subunits can hydrolyze maltose, nigerose and kojibiose but all isomaltase activity is present in the $N$-terminal subunit. Analogous to MGAM, neither subunit can hydrolyze trehalose.

\section{Trehalase activity in the small intestine}

Trehalase (TREH, EC 3.2.1.28) is the endogenous glycosidase responsible for the hydrolysis of trehalose ( $\alpha$-Dglucopyranosyl- $\alpha$-D-glucopyranoside), which is a nonreducing disaccharide of $1,1^{\prime}$ - $\alpha, \alpha^{\prime}$-linked glucose moieties [19]. TREH makes up about $0.1-0.3 \%$ of total protein in the intestinal brush border membrane [29] and is also expressed in the renal tubular epithelium $[19,46,47]$. As trehalose is mainly found in funghi, yeast and insects it is no surprise that most known trehalases are found in fungi, insects and bacteria $[19,48,49]$. Trehalase has an inverting mechanism relying on an acid catalysed $\left(\mathrm{Asp}^{312}\right)$ departure of the leaving group followed by a base catalysed $\left(\mathrm{Glu}^{496}\right)$ nucleophilic 


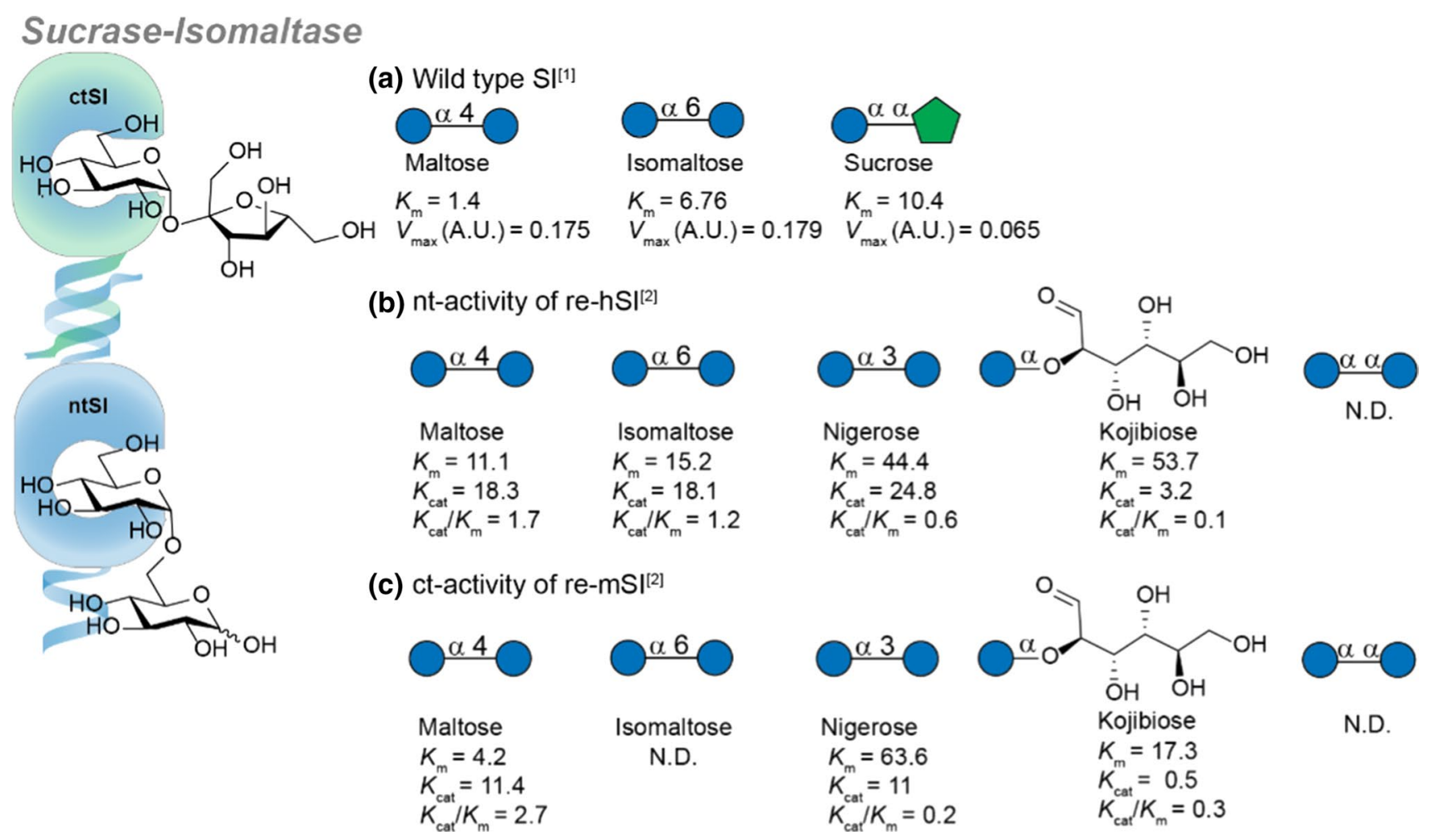

Fig. 4 Substrate specificity of sucrase-isomaltase (SI). a The affinity of substrates in wild-type SI. b The N-terminal activity of human SI (hSI). c The C-terminal activity of mouse SI (mSI). Values are

attack of water, yielding equimolar amounts of $\alpha$ - and $\beta$-Dglucose from trehalose (Fig. 2c) [19, 27, 50, 51]. Though the expression of trehalase in humans is limited, TREH deficiency can lead to diarrhea in combination with foods high in trehalose such as mushrooms [52].

Next to trehalose, epimers such as $\alpha, \alpha$-glc-gal, $\alpha, \alpha$-glcallose, $\alpha, \alpha$-glc-xylose and 6'-deoxytrehalose are hydrolysed by human trehalase (Fig. 5a) albeit with lower efficiency compared to trehalose. In addition, $\mathrm{C}-2$ modification are not tolerated as $\alpha, \alpha$-glc-man and $\alpha, \alpha$-glc-glcN showed competitive inhibition of TREH. The $\alpha$-glycosidic linkage seems essential for activity and recognition as related $\alpha, \beta$ - or $\beta, \beta$ trehalosides are not recognized. Furthermore, $\alpha, \alpha$-analogues lacking a glucoside do not show affinity for TREH, suggesting glucose is the glycon in asymmetric active substrates. The aglycone may not need to be a carbohydrate as studies using rabbit kidney trehalose is showed enzymatic hydrolysis of both $\alpha$-D-glucosyl fluoride $\left(35.6 \mu \mathrm{mol} \mathrm{min}^{-1} \mathrm{mg}^{-1}\right)$ and $\beta$-D-glucosyl fluoride $\left(0.51 \mu \mathrm{mol} \mathrm{min}{ }^{-1} \mathrm{mg}^{-1}\right)$, the former even faster than $\alpha, \alpha$-trehalose $\left(14.3 \mu \mathrm{mol} \mathrm{min}^{-1} \mathrm{mg}^{-1}\right)$ $[19,53]$. In contrast, trehalase is competitively inhibited by phlorizin, sucrose and TRIS [tris(hydroxymethyl)aminomethane)] [47, 54]. For further insight in the role of trehalose and trehalase in organisms we refer to a review from Carroll and coworkers [55]. reported as: $K_{\mathrm{m}}(\mathrm{mM})$ and $K_{\mathrm{cat}}$ in $\left(\mathrm{s}^{-1}\right)$. References used: ref 1 [9], ref 2 [36]. N.D. not detected

\section{The function of lactase-phlorizin hydrolase in the small intestine}

Lactase-phlorizin hydrolase (LPH, EC 3.2.1.23/62) is the major $\beta$-glycosidase of the intestinal microvillus membrane and accounts for the hydrolysis of lactose and most $\beta$-glycosylated xenobiotics (e.g. phlorizin and glycosylated flavonoids, Fig. 7a) [11]. LPH is the most important glycosidase in post-natal life in mammals, since the main ingested carbohydrate during this period is lactose. In most mammals its expression levels decrease as the organism grows older and the significance of lactose in daily nutrient ingestion diminishes [19]. The ultimate absence of LPH results in lactose intolerance and this is the most common intestinal disorder associated with decreased activity of glycosidases [56]. Lactose intolerance is classified in four different types in which the extreme case is the autosomal recessive disorder: congenital lactase deficiency (CLD). The very low lactase activity present is causes severe symptoms like watery diarrhoea meteorism and malnutrition. This is life threatening for new borns and needs immediate removal of lactose from the diet and displacement with milk-substitutes. For a comprehensive overview of LPH-pathology we refer to a recent review by Naim and coworkers [57]. Analogous 
Fig. 5 Relative substrate affinity of human TREH. a Substrates cleaved by TREH and $\mathbf{b}$ substrates not cleaved by TREH. $K_{\mathrm{m}}$ and $K_{\mathrm{i}}$ are expressed in $\mathrm{mM}$, the $V_{\max }$ is expressed relative to trehalose (100\%) [10]. N.I (no interaction)

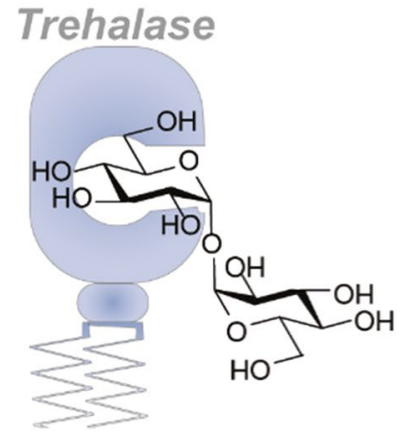

(a) TREH active substrates

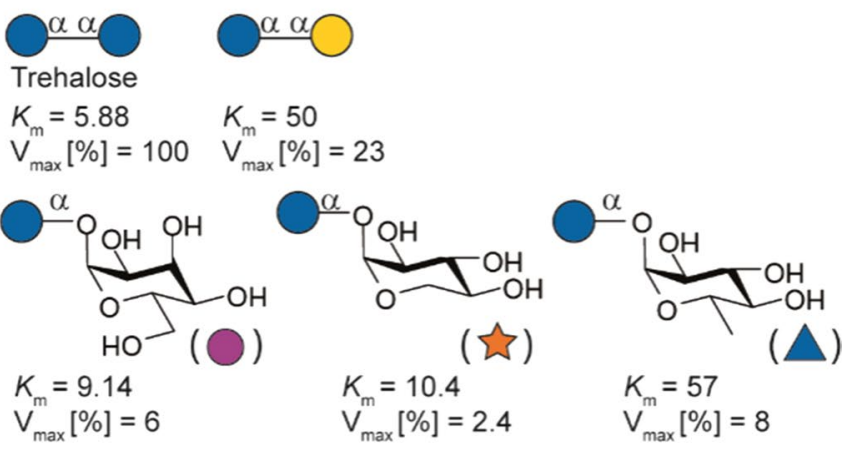

(b) TREH inactive substrates
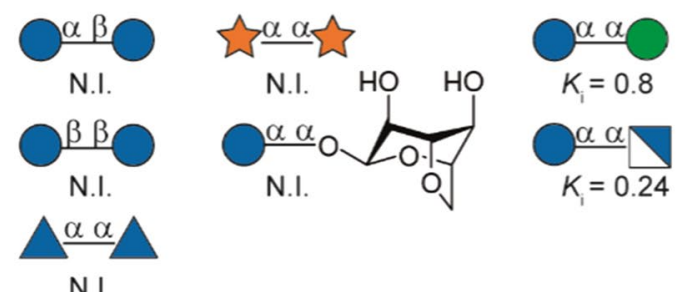

N.I.

\section{LPH activity for lactose derivatives}

Pioneering SAR-studies were performed by Norén et al. [11] and Enevoldsen et al. [65] with purified LPH from humanand pig intestinal tissue (hLPH and pLPH respectively). The activity for most substrate studied was reported as percentage of the activity of hLPH relative to lactose and is summarized in Fig. 6a. In addition, the $K_{\mathrm{m}}$ of the natural substrate was measured and compared to gluco-analogue cellobiose ( $21 \mathrm{mM}$ and $4.4 \mathrm{mM}$ respectively). Synthetic carbohydrate derivatives conjugated to aromatic aglycons showed a decrease in activity compared to lactose. Interestingly, the configuration of the 4-OH of the non-reducing end does not significantly impact the hydrolytic activity (glucose). This is again reflected by the hydrolytic activity towards natural saccharides. Cellobiose, -triose and -tetraose still show moderate activity. Interestingly, LPH can also hydrolyze cellulose although the limited solubility of cellulose diminishes its nutritional value [11]. In contrast, the C-6 oxidized analogue glucuronic acid shows little activity. The limited access to human intestine samples have resulted in most other studies using LPH from other mammalian species such as sheep LPH (sLPH). The substrate specificity of sheep sLPH was determined by Martín-Lomas et al. [59, 64] with synthetic lactoside derivatives (Fig. 6b). It is expected that the $K_{\mathrm{m}}$ and $V_{\mathrm{m}}$ values obtained in this study are only for the lactase subunit since cellobiose and lactose do not inhibit the phlorizin hydrolase. This is underlined by hydrolysis studies which show that methyl $\beta$-lactoside as well as lactal are exclusively 


\section{Lactase phlorizin hydrolase}

(a) Relative activity $h L P H^{[1]}$

Synthetic derivatives
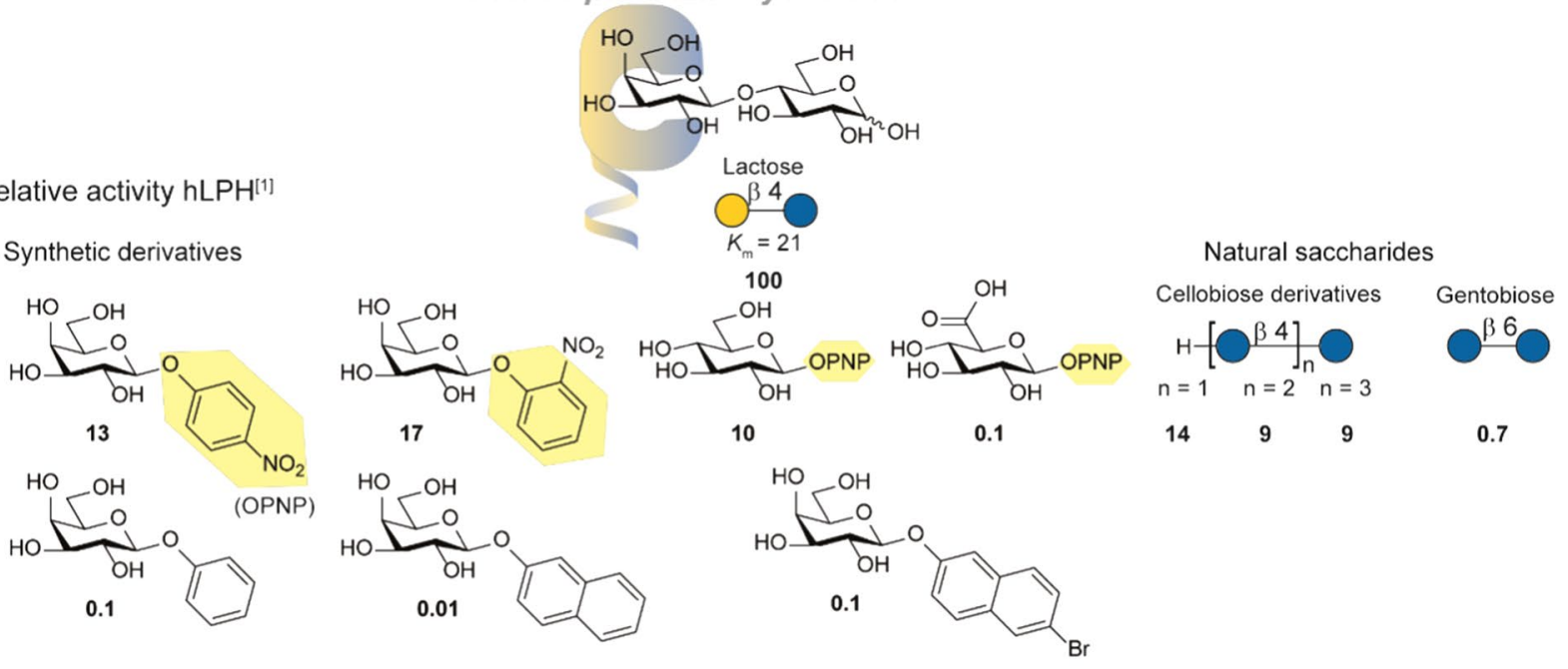

(b) Affinity sLPH lactose derivatives ${ }^{[2,3]}$
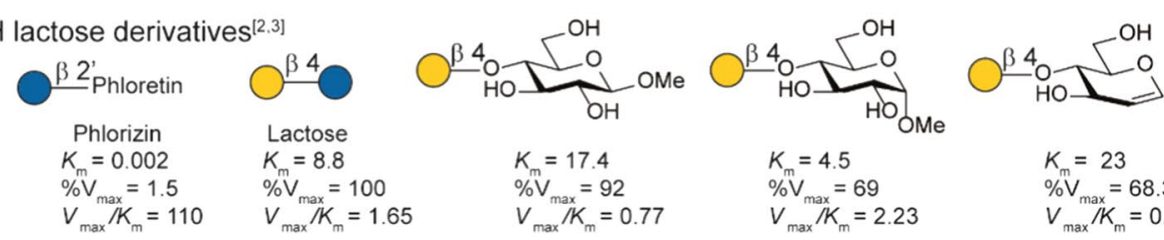

$K_{\mathrm{m}}=8.8$

$V_{\max } / K_{\mathrm{m}}=1.65$

$$
\begin{aligned}
& K_{m}=4.5 \\
& \% V_{\max }=69 \\
& V_{\max } / K_{m}=2.23
\end{aligned}
$$

$K_{m}=23$

$\% \mathrm{~V}_{\max }=68.3$

$V_{\max }^{\max } / K_{\mathrm{m}}=0.43$

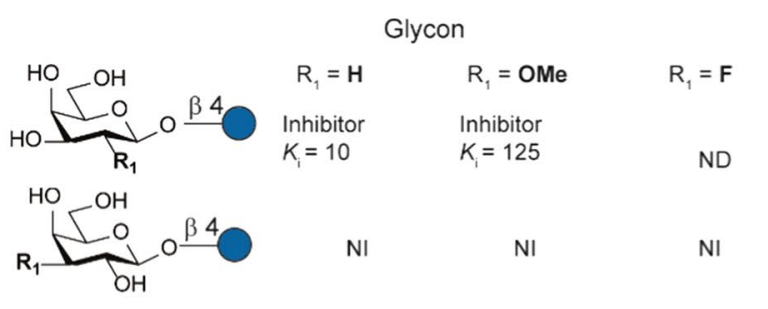

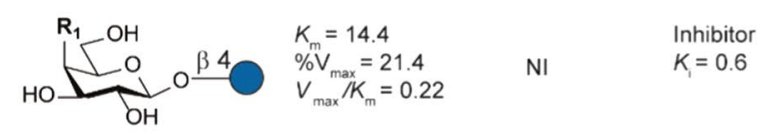

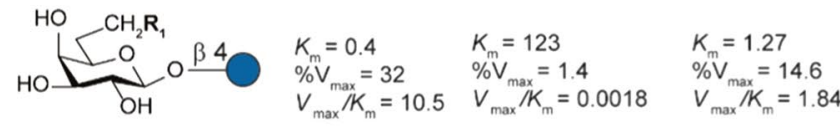

Fig. 6 SAR study of the lactase-site of LPH. a An overview of the relative activity of hLPH towards various synthetic and natural carbohydrates. The activity is reported in percentages relative to lactose. b An overview of the aglycon and glycon affinity of sheep LPH (sLPH)

hydrolyzed at the lactase site [64]. Since the $\alpha / \beta$-equilibrium in case of reducing end sugars complicates specific $K_{\mathrm{m}}$ determination, the lactoside analogues studied were substituted at the reducing end. Comparison of the methyl $\alpha$-lactoside and methyl $\beta$-lactoside showed both are hydrolyzed by sLPH, although there is a slight preference for the $\alpha$-anomer. This is in line with the observation of Norèn et al. (cellotriose, cellotetraose and cellulose are hydrolyzed) that C-1 modifications on $n+2$ position are allowed [64, 65].

Systematic deoxygenation, methylation of fluorination of the hydroxyls of the galacto-moiety reveal
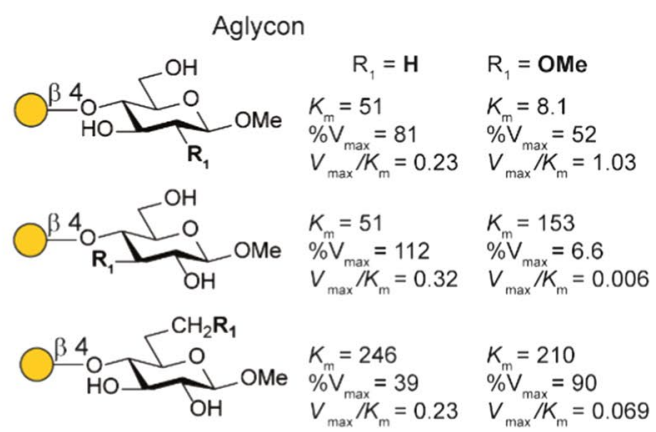

$K_{m}=246 \quad K_{m}=210$

$\begin{array}{ll}K_{m}=246 & K_{m}=210 \\ \% V_{\text {max }}=39 & \% V_{\text {max }}=90\end{array}$

$V_{\max } / K_{m}=0.23 \quad V_{\max } / K_{m}=0.069$

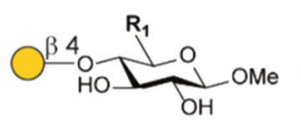

$R_{1}=\mathbf{H}$
$K_{m}=>300$
$\% V_{\text {max }}=11$
$V_{\max } / K_{m}=0.006$

$\mathrm{R}_{1}=\mathrm{CH}_{2} \mathrm{~F}$
$\mathrm{~K}_{m}=292$
$\% \mathrm{~V}_{\max }=170$
$V_{\max } / K_{m}=0.08$

$\mathrm{R}_{1}=\mathrm{CH}_{2} \mathrm{I}$

$\mathrm{NI}$

towards synthetic lactose derivatives. $K_{\mathrm{m}}$ and $K_{\mathrm{i}}$ are reported in $\mathrm{mM}$, $V_{\max }$ is reported as percentage relative to lactose. NI (no interaction), ND (not determined), PNP (4-nitrophenol). References used: ref 1 [11], ref 2 [64], ref 3 [59]

an interesting trend in glycon-substrate specificity. Deoxygenation or methylation of the galactosyl C-2' hydroxyl results in a competitive inhibitor which is most pronounced in the case of the C-2' deoxy derivative $\left(K_{\mathrm{i}}=10 \mathrm{mM}\right)$. It has been proposed that this HO-2' is vicinity of a carboxylate group in the active site and is necessary to stabilize the intermediate glycosyl oxocarbenium ion or is involved in the formation of a covalent galactosyl-enzyme intermediate [59, 64, 66]. Modification of the C-3' position is not permitted in all studied derivatives and showed neither hydrolysis nor inhibition, 


\section{Lactase phlorizin hydrolase}

(a) Major subclasses of flavonoids

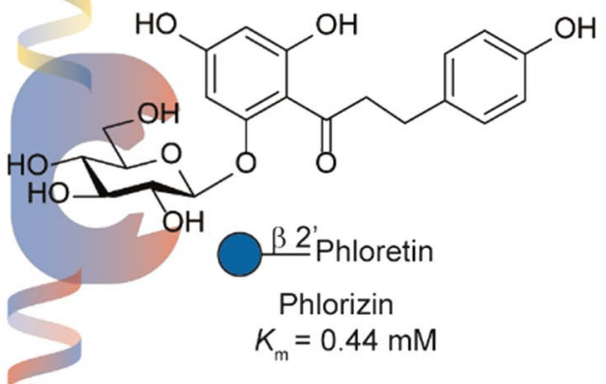<smiles>[R]O[14CH2][14CH2][14CH2]O[14CH2]O</smiles>

Luetolin (L), $\mathrm{R}_{1}=\mathrm{OH}$ Apigenin (A), $R_{1}=H$

Flavanone<smiles>[R]c1cc([C@H]2CC(=O)c3c(O)cc(O)cc3O2)ccc1O</smiles>

(b) hLPH activity ${ }^{[1]}$

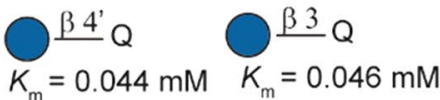

$$
\begin{aligned}
& K_{\text {cat }}=7.5 \quad K_{\text {cat }}=6.3 \\
& K_{\text {cat }}^{\text {cat }} / K_{\mathrm{m}}=170 \quad K_{\text {cat }}^{\text {cat }} / K_{\mathrm{m}}=137 \\
& \frac{\beta 7}{D a} \\
& K_{\mathrm{m}}=0.149 \\
& k^{m}=2.1 \\
& k_{\text {cat }} / K_{\mathrm{m}}=14 \\
& \frac{\beta 7}{G e} \\
& K_{\mathrm{m}}=0.085 \\
& k^{m}=6.5 \\
& k / K_{m}=77
\end{aligned}
$$

Isoflavone
Quercetin (Q), $\mathrm{R}_{1}=\mathrm{OH}$

Kaempferol $(\mathrm{K}), \mathrm{R}_{1}=\mathrm{H}$ Isorhamnetin (I), $\mathrm{R}_{1}=\mathrm{OMe}$

Flavanol<smiles>[R]c1cc([C@@H]2Oc3cc(O[Tl])cc(O)c3C[C@H]2O)cc(O)c1O</smiles>

Gallocatechin (Ga), $\mathrm{R}_{1}=\mathrm{OH}$ Catechin (Ca), $\mathrm{R}_{1}=\mathrm{H}$<smiles>[R]c1cc(O)cc2occ(-c3ccc(O)cc3)c(=O)c12</smiles>

Genistein $(\mathrm{Ge}), \mathrm{R}_{1}=\mathrm{OH}$

Daidzein (Da), $\mathrm{R}_{1}=\mathrm{H}$

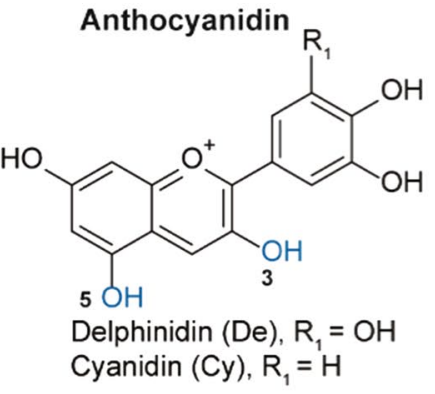

(c) SLPH active substrates ${ }^{[2]}$

(d) $\mathrm{SLPH}$ inactive substrates ${ }^{[2]}$

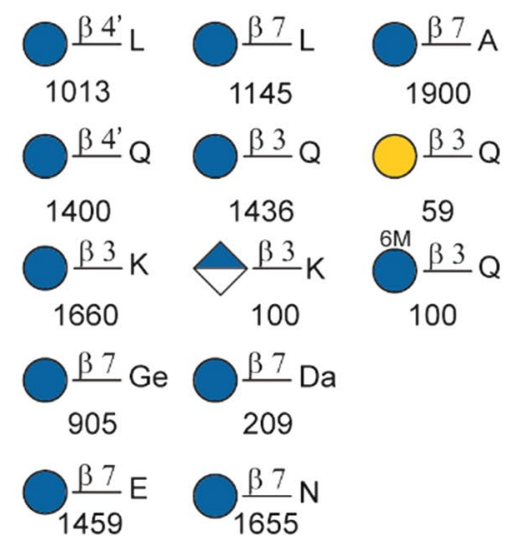

Fig. 7 SAR study of the phlorizin-site of LPH. a An overview of the flavonoid subclasses. Potential glycosylation sites highlighted in blue. b Activity of human LPH (hLPH) towards a selection of flavonoids. c Relative activity of sheep LPH (sLPH) relative to phlorizin (100). d Overview of the sLPH inactive flavonoids. References used: ref 1 [67], ref 2 [68] 
indicating that the $\mathrm{HO}-3^{\prime}$ is a critical polar group for substrate recognition. Most likely, the $\mathrm{C}-3^{\prime}$ position is involved in hydrogen bond donation $[59,66]$. The C-4' position modification are tolerated as cellobiose and other glucosides are hydrolyzed by lactase [64]. Hence, deoxygenation retains affinity though a decrease in hydrolysis rate is observed. Conversely, methylation or fluorination leads to loss of affinity or inhibition respectively. A C-4' fluor derivative is an inhibitor suggesting that it fits in the active site, but the fluorine likely destabilizes the reaction pathway via the oxocarbenium cation due to its electronegativity [59]. The trend observed with respect to $\mathrm{C}-4{ }^{\prime}$ modification suggests LPH to be classified as a $\beta$-glycosidase instead of only a $\beta$-galactosidase. The C-6' deoxy derivative showed even higher affinity than methyl $\beta$-lactoside, indicating that a hydrophobic environment is present in the active site on this position. High affinity was also observed in case of the $6^{\prime}$-deoxy-6'-fluoro lactoside. In contrast to the C-4' fluor derivative, the C-6' fluor is hydrolysed, suggesting a different impact on the oxocarbenium cation. Larger substituents at the C-6' position were poorly hydrolysed.

In extend, the aglycon substrate specificity was studied. It was proposed that the glucose moiety is important for binding since lactulose [65] and $\beta$-Dgalactopyranosyl-( $1 \rightarrow 4)$-1,6-anhydroglucose are not hydrolysed by lactase. The C-2-deoxy and C-3- deoxy derivatives of the glucose moiety show only a similar threefold increase in $K_{\mathrm{m}}$, suggesting that they play a small role in substrate recognition. Methylation at these positions, however shows a dramatic decrease in catalytic efficiency $\left(V_{\max } / K_{\mathrm{m}}\right)$ in case of C-3 whereas C-2 methylation is relatively unaffected. These observations indicate that though HO-3 is not critical for binding, the local environment is sterically crowded. The C-5/C-6 positions seem least tolerant to modifications as deoxygenation, methylation, fluorination, iodination or the xylose derivative all show sharp increase of $K_{\mathrm{m}}$. This indicates that the HO-6 is important for efficient enzyme binding and it probably participates as a hydrogen bond donor in the periphery of the binding site.

These SAR-studies on glycon and aglycon summarize the substrate preference of LPH towards lactose derivatives. To summarize, the C-2 and C-3 position of the glycon are crucial for substrate recognition and catalytic activity. Small structural modifications on the C-4 are allowed to a certain extend whereas the C-6 position shows more tolerance. In all cases, methylation results in loss of activity suggesting no space for extension at the non-reducing end. At the +1 (aglycon) site modifications are allowed at $\mathrm{C}-1$ and $\mathrm{C}-2$ and to a lesser extend at $\mathrm{C}-3$. The $\mathrm{C}-6$ positions in contrast is crucial for substrate affinity.

\section{LPH activity for hydrophobic derivatives}

LPH is active against a wide variety of glycosylated flavonoids (for structural overview see Fig. 7a). Though the hydrolytic activity against phlorizin is present at the phlorizin hydrolase site, most flavonoid hydrolysis is observed at the lactase site. This is remarkable since flavonoid derivatives display a high similarity to phlorizin [67]. In the same study, the activity against flavonols (quercetin) and isoflavones (genistein and daidzein) was determined (Fig. 7b). Comparable $K_{\mathrm{m}}$ and $K_{\text {cat }}$ was observed in the hydrolysis of the flavanols independent on the substitution site. Interestingly, the meta-substituent relative to the glycosylation site in isoflavones had a high impact showing a five-fold drop in activity in case of non-substituted isoflavone (daidzein7 -glucoside). Additional studies performed with sLPH showed a high activity in most glucosylated flavonoids (Fig. 7c). Similar trends in SLPH activity trend towards daidzein-7-glucoside and the genistein analogue was observed as in hLPH. Though lower compared to the glucosylated analogues, activity was observed towards 3-galactosylated quercetin as was for 3-glucuronated kaempferol. Interestingly, also malonated glucoside-3-quercetin also was hydrolysed by the enzyme. $\alpha$-L-rhamnosylated, $\beta$-D-xylosylated, $\alpha$-L-arabinosylated or rutinated quercetins proved no substrate as also observed for kaempferol disubstitued with $\alpha$-Lrhamnosylated and rutinose (Fig. 7d). In addition, sLPH did not show activity towards cyanidins. More on the absorption of flavonoids and their absorption model can be found in a paper by Kroon et al. [68]. For a comprehensive overview on flavonoid absorption we refer to a review by Jiang et al. [69].

\section{Cytosylic beta glucosidase}

Human cytosolic $\beta$-glucosidase (hCBG, 3.2.1.21) is a broad specificity $\beta$-glycosidase enzyme involved in the intracellular hydrolysis of $\beta$-glycosylated xenobiotics and glucosylceramides. hCBG is mainly expressed in the cytosol of the liver, kidney, intestine and spleen [70, 71]. Since hCBG acts as glucosylceramidase (GC) it is also reported as khloto related protein (KlrP). To avoid confusion we will only refer to hCBG [72]. Interestingly, the activity as GC has prompted to study possible involvement of CBG in Gaucher disease, a recessively inherited lysosomal storage disorder resulting. Gaucher disease is normally linked to deficiency in lysosomal GC (3.2.1.45) and cause massive accumulation of glucosylceramide in tissue macrophages leading e.g. enlarged spleen and liver, bone pain and bleeding problems. It was found that in some patients soluble $\beta$-glucosidase was impaired [73] this observation combined with Hayashi and co-workers' report about GC activity [12] suggested involvement of CBG. However, findings from the group of Beutler [74] and the group of Aerts [75] disputed this and found 
hardly any activity towards natural glucosylceramide. In addition, inhibition or impairment of CBG did not show elevated intracellular glucosylceramide levels nor correlation with type 1 Gaucher disease severity. Like all GH1 $\beta$-glucosidases, hCBG carries two glutamate residues in its active site $\left(\mathrm{Glu}^{165}\right.$ and $\left.\mathrm{Glu}^{373}\right)$, that catalyse the hydrolysis with overall retention of configuration in two steps (see Fig. 3b) [76]. First the aglycone is protonated and departs after nucleophilic attack of the glutamate residue resulting in the formation of an $\alpha$-linked covalent glycosyl-enzyme intermediate. The glycone undergoes conformational changes from a chair via a skew boat to the half-chair transition state $\left({ }^{4} \mathrm{C}_{1} \rightarrow{ }^{1} \mathrm{~S}_{3} \rightarrow{ }^{4} \mathrm{H}_{3}\right)$, which changes further to the $\alpha$-linked glycosyl enzyme intermediate in the chair conformation via a skew boat $\left({ }^{4} \mathrm{H}_{3} \rightarrow{ }^{1} \mathrm{~S}_{3} \rightarrow{ }^{4} \mathrm{C}_{1}\right)$ [26, 77]. Interestingly, hCBG hydrolytic activity is not limited to glucosides as it can also hydrolyse other hexoses and pentoses (see Fig. 8b). For a full analysis of the crystal structures we refer to studies by Juge and coworkers who employed a model structure together with the crystal structure of hCBG to investigate the aglycone specificity and the structural motifs/domains compared to other GH1 family members [76, 78]. In addition, the crystal structure of the covalent glycosyl intermediate was elucidated by Kakuta et al. [72]. Importantly, they confirmed the double displacement hydrolysis mechanism of $\mathrm{hCBG}$ and potential transition state stabilization by a $2-\mathrm{OH}$ water interaction.

Most SAR studies focus on the function of hCBG in the hydrolysis of xenobiotic compounds, the endogenous role of CBG however, was revealed in 2007 as glycosyl ceramidase (GC) [12]. Ito and coworkers confirmed GC activity by incubation of radio- and fluorescent labelled glycosyl ceramides (Fig. 8a). Though a high affinity was found, the overall activity is low compared to simple model substrates such as 4-methylumbelliferyl-(MU)- $\beta$-glucose and $-\beta$-galactose. The slow turnover can be explained by the slow rate of aglycon departure which is still tightly bound. In all combinations, glucose showed to be a better substrate than galactose as glycon. Juge and coworkers expressed hCBG from the liver in Pichia pastoris (reCBG) and performed a comprehensive study of glycon and aglycon specificity [70]. On the glycon site (Fig. 8b), reCBG showed a preference for equatorial linked sugars as PNP- $\alpha$-glucose is not a substrate for the enzyme [70, 71]. In contrast, a broad variety of sugars was tolerated as long as the C-2 hydroxyl group is equatorially oriented (the epimer PNP- $\beta$-mannose acts as inhibitor). Remarkably, $\beta$-D-fucose and $\alpha$-L-arabinopyranose showed a higher $K_{\mathrm{cat}} / K_{\mathrm{m}}$ value than glucose. Such trends are observed more often in GH1-class hydrolases and the origin has been extensively studied by Withers and coworkers on $\beta$-glycosidase from Agrobacterium. sp. [79, 80].

The aglycon specificity of hCBG has mainly been focussed on xenobiotic $\beta$-D-glycosides (for structural details on flavonoids see Fig. 7a). A variety of flavonoids was tested with reCBG (Fig. 8c). $\beta$-D-glucosides of isoflavones, flavonols and flavones were good substrates, while the saturated flavanone glucosides were hydrolysed less efficiently (lower catalytic efficiency constants $k_{\mathrm{cat}} / K_{\mathrm{m}}$ ). This indicates that a flat aromatic molecule is a favourable substrate compared to aliphatic analogues. CBG shows a high specificity for regio-chemistry. Glucosylation at the $4^{\prime}$ and 7-position on the flavonoid skeleton are well tolerated whereas in contrast to LPH, substitution at the 3-position leads to loss of catalytic activity. This decrease in affinity of the 3-position by local steric hindrance was later rationalized by modelling studies [70, 76]. Furthermore, malonylation of the glucose moiety e.g. in case of daidzein-7-Glc results in a significant decrease in both hydrolysis rate and affinity. Similar to LPH, $\alpha$-L-rhamnosylation as present in naringenin-7-rutonise and hesperitin-7-rutinose is not accepted. In addition, glucosides of dihydrochalcones (phlorizin), anthocyanins, glucuronides (quercetin-4'-Glu) and were not found to be substrates (Fig. 8f) [70]. The enzyme showed activity towards cyanogenic glucosides (Fig. 8e, amygdalin and prusin) and phenolic glucosides (Fig. 8d, arbutin and salicin) though these were hydrolysed least efficiently $(\sim 10 \%$ and $1 \%$ of the average rate observed for flavonoid monoglucosides respectively). Before hCBG is able to hydrolyse these compounds, they need to be transported to the cytosol. Glycoside transporters play an important role in monosaccharide- and glycoconjugate transport over the apical membrane and will be discussed in the next section.

\section{Glycoside transporters: analysis of affinity and transport}

The study of substrate specificity of transporters is challenging compared to enzymes involved in chemical conversion. The latter class can be studied in cell free systems whereas transporters have to be studied expressed in membranes. Standard methods for transport discussed in this review involve radiotracers, electrophysiology or HPLC-MS methods. Radiotracers are e.g. ${ }^{3} \mathrm{H}-,{ }^{14} \mathrm{C}$ or ${ }^{18} \mathrm{~F}$ radiolabelled derivatives of sugars which are added to an expression system and their transport can easily be monitored over time. They do however require chemical modifications with radioactive isotopes of the sugar to be studied. Often a standard radio-labelled compound of pre-determined $K_{\mathrm{m}}$ such as $\left[2,6-{ }^{3} \mathrm{H}\right]$-2-deoxyglucose is used and the substrates of interest are co-incubated. The decrease in uptake of the radiotracer a $K_{\mathrm{i}}$-value can be determined but no direct evidence of transport is obtained. Electrophysiology studies are more direct but require an electrogenic transporter such as the sodium dependent glucose transporters (SGLT). Xenopus laevis oocytes are often used as expression system of the 


\section{Cytosolic Beta Glucosidase}

(a) CBG specificty towards endogenous substrates ${ }^{[1]}$

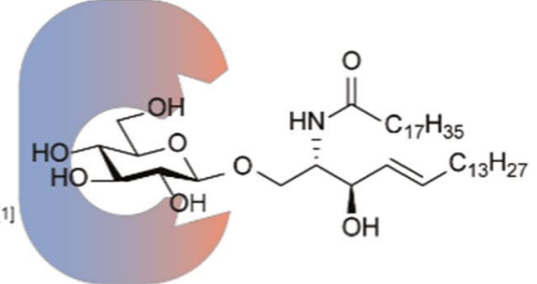

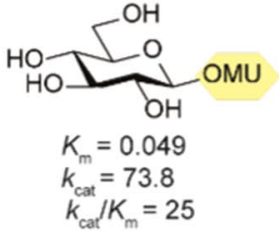

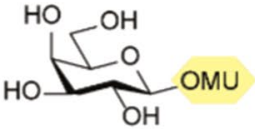

$K_{\mathrm{m}}=0.144$

$k_{\text {cat }}=94.4$

$k_{\mathrm{cat}} / K_{\mathrm{m}}=11$

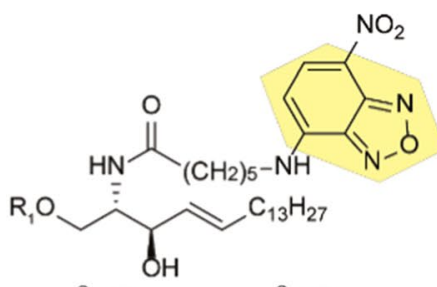

$R_{1}=\underline{\beta} \bigcirc \quad R_{1}=\underline{\beta} \bigcirc$

$K_{\mathrm{m}}=0.005 \quad K_{\mathrm{m}}=0.002$

$k_{\mathrm{cot}}^{\mathrm{m}}=7.26 \quad k_{\mathrm{m}}^{\mathrm{m}}=1.53$

$k_{\mathrm{cat}} / K_{\mathrm{m}}=1.57 \quad k_{\mathrm{cat}} / K_{\mathrm{m}}=0.75$

(b) CBG Glycon specificityl[2]
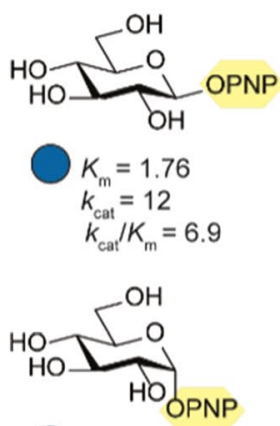

N.A.
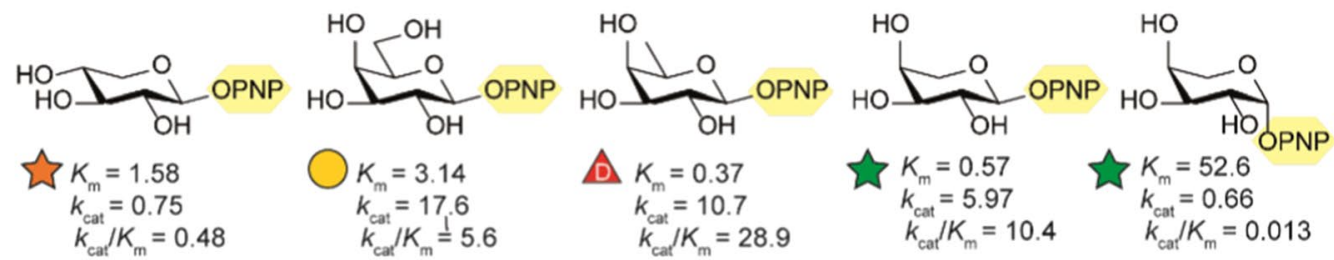
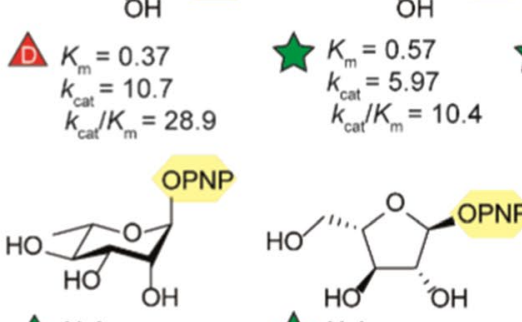

$\triangle$ N.A.

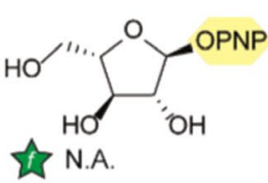

$\Leftrightarrow$ N.A (c) Flavanoids ${ }^{[2]}$

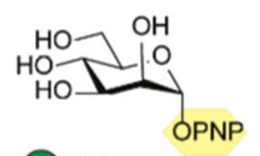

N.A. (d) Small phenols ${ }^{[2]}$

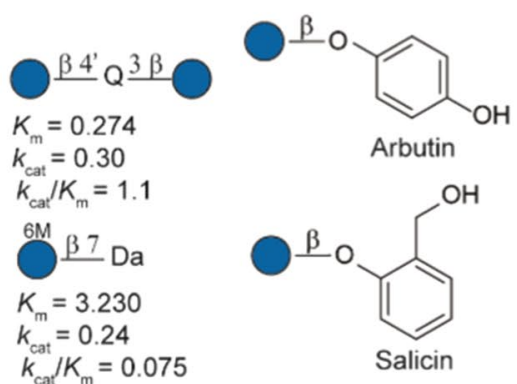

(e) Cyanogenic glycosides ${ }^{[2]}$

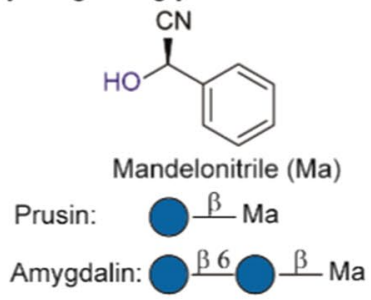

(f) Inactive substrates ${ }^{[2]}$

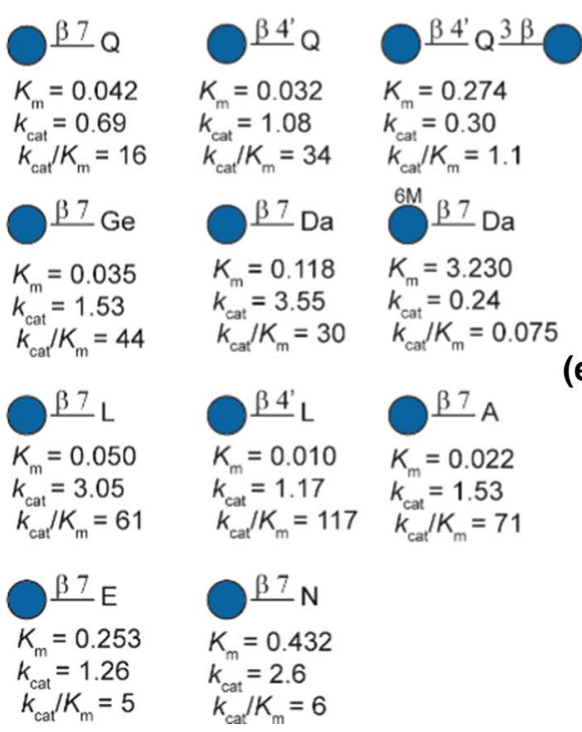

Fig. 8 Overview of SAR-studies on CBG specificity: a Overview of the activity of CBG towards glycosylceramides $\left(K_{\text {cat }}\right.$ in s $\left.{ }^{-1}\right)$. b Overview of glycon specificity. Activity towards flavonoids (c). Exact activity towards small phenolic substrates (d) and cyanogenic gly- cosides (e) were not reported. f Studied substrates which were not hydrolyzed by CBG. Referneces used: ref 1 [12], ref 2 [70]. $K_{\mathrm{m}}$ is reported in mM. N.A. Not Active 
human-cDNA encoding for the transporter of interest. Next, they are used in combination with two-electrode voltage clamp or patch-clamp techniques. The measures current is dependent on the substrate and its concentration and form a reliable system to study direct substrate affinity $\left(K_{\mathrm{m}}\right)$ and even transport $\left(V_{\max }\right)$. Alternatively, transport studies involving HPLC-MS analysis can be used in combination with a cell line that can grow into a monolayer system mimicking the intestine such as human colon cancer cell line Caco2. The substrates of interest can be added at the apical or basolateral side and their transport can be measured with HPLC-MS. Care has to be taken as Caco-2 is a cancer cell line which can also express elevated levels of GLUT1, and in addition their expression into a monolayer is slow and time-consuming. Finally, it goes without saying that specific transport has to be assessed with the correct control experiments, requiring use of a known specific inhibitor as the situation especially in multi-cell systems may not be trivial.

\section{Apical transport}

The major first pass carbohydrate transporters involved in intestinal monosaccharide uptake are the active sodium dependent glucose transporter (SGLT1) and the passive facilitative fructose transporter (GLUT5). Although both transporters differ in uptake mechanism and substrate specificity, the transport is coupled to a phosphorylation pathway that ensures a positive gradient over the membrane (Fig. 1). Interestingly, the involvement of other transporters in monosaccharide uptake like GLUT7 [81], GLUT9 [82] and GLUT12 [83] are suggested in literature but under debate as their exact role in monosaccharide transport awaits to be revealed $[84,85]$. Since these transporters are expressed to a much lower extend than SGLT1 and GLUT5, this review will focus on the latter two.

\section{Carbohydrate transport by SGLT1}

SGLT1 (SLC5-family) is the major glucose-transporter of the intestinal tract [86] and is mainly expressed, but not limited to, the brush border membrane of the small intestine. Additionally, SGLT1 is expressed in the trachea, heart brain and various other tissues (Table 1). First cloned and studied by Wright and coworkers in 1987 [87], SGLT1 selectively transports glucose and galactose with millimolar affinity [13, 88] $\left(K_{\mathrm{m}}=0.5 \mathrm{mM}\right.$ for both substrates) over the apical membrane (Fig. 1, top right). Transport of D-glucose is sodium dependent in a stoichiometry of one monosaccharide per two sodium ions and is therefore a symport transporter. This means that glucose absorption is not limited to high apical glucose levels obtained after consumption but also in between meals when a low glucose concentration is present. The sodium gradient is maintained by $\mathrm{Na}^{+} / \mathrm{K}^{+}$-ATPase which provides extracellular transport of three sodium ions for two potassium ions, gaining one charge per cycle. SGLT1 is also capable of facilitating water transport which is unaffected by substrate binding [89]. Defects in the SGLT1 gene are related to the autosomal recessive disease glucose/ galactose malabsorption which is characterized by failure of glucose and galactose absorption in the small intestine [90].

\section{Transport mechanism of SGLT1}

Although no crystal structures of human SGLTs are known thus far, a crystal structure of a bacterial homolog (vSGLT) [92] with a high similarity has been used as a template to model hSGLT1 $[93,94]$. In addition, recent studies by Lapointe and coworkers showed that SGLT1 is expressed as a homodimer via an extracellular disulfide bridge [95]. Figure 9 shows the proposed six state mechanism of hSGLT1. The first step in the process involves the binding of $\mathrm{Na}^{+}$ in the binding pocket to open the outside faced gate. Interestingly, binding of the first $\mathrm{Na}^{+}$promotes binding of the second $\mathrm{Na}^{+}$and also sugar binding [96]. In the next step, the sugar binds in the pocket and is trapped by closure of the outside gate. The binding of glucose and closure of the outside gate causes an allosteric interaction and changes the conformation from outward occluded to inward occluded. Subsequently, the inward gate is opened to release glucose and the sodium. It should be noted that the rate of transported is governed by the opening and closing of the outer and inner gates [91]. After dissociation of the substrate, the inward gate closes and the protein rests in the inward facing ligand free state. The final step, before the process can repeat itself, is the conformational change from inward facing to outward facing ligand free state after which sodium can bind in the pocket again to open the outside gate. At close to $V_{\max }$ conditions, the turnover rate (defined as the number of complete cycles each protein performs per second) was $13.3 \mathrm{~s}^{-1}$ based on the uptake of $\alpha$-methyl glucose. For a detailed study of the structure and kinetics of human SGLT1 we refer to Wright and coworkers [94].

\section{Substrate affinity of SGLT-1}

Although no crystal structure of human SGLT1 is known yet, SGLT1 is arguably the best studied human monosaccharide transporter. Since the transport of the sugar is directly related to the transport of sodium, two-electrode voltageclamp techniques can be used to study the substrate transport and affinity. Figure 10 depicts a overview of the substrate affinity of hSGLT1 [93]. The transport of a wide variety of natural monosaccharides and synthetic monosaccharide derivatives have been tested in oocytes and are grouped accordingly. The affinity is reported as $K_{0.5}$ at constant $I_{\max }$ relative to methyl $\alpha$-glucose, details are mentioned in 


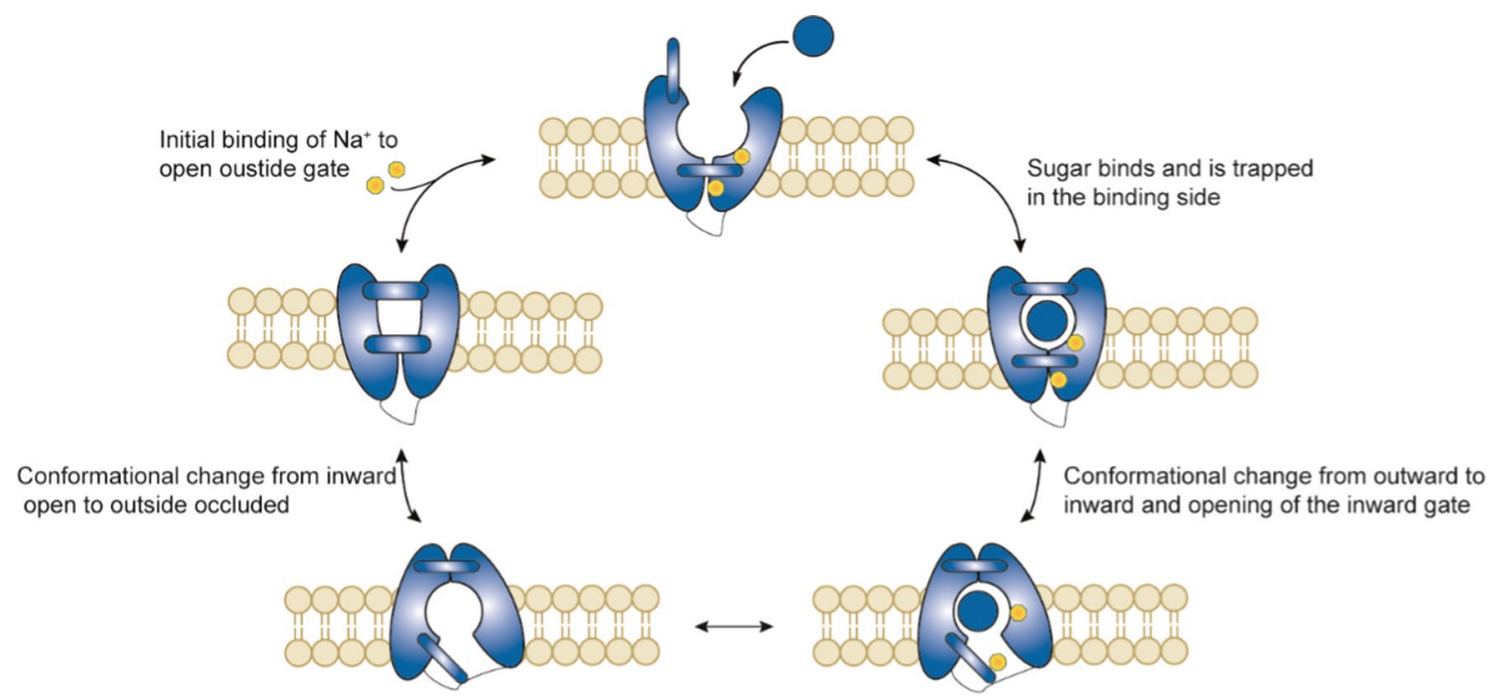

Fig. 9 Schematic overview of the proposed 5-state model of SGLT1 during glucose transport ( adapted from Wright and coworkers, 2017) [91]

Fig. 10. The trends observed in these studies give crucial information about which carbohydrate substituents determine the affinity of the substrate. D-glucose and D-galactose are the only common natural sugars accepted for transport. Epimers at C-2 (D-mannose) and C-3 (D-allose) lead to complete loss of substrate transport (Fig. 10a). Also the important nutrient D-fructose is not accepted, neither are L-sugars: L-glucose, L-fucose and L-xylose. Interestingly, 6-deoxyglucose (D-quinovose) is still transported though the affinity is six fold lower than D-glucose. Systematic positional fluorination (Fig. 10b) reveals that although the affinity decreases, substitution is accepted at C-3, C-4 (both galacto and gluco-stereochemistry) and C-6. Interestingly, 4-fluorodeoxyglucose (4-FDG) shows a lower $K_{0.5}$ than D-glucose. Importantly, fluorination at C-2 leads to complete loss in affinity as is also observed in case of: amino derivatization (2-ADG), and deoxygenation (Fig. 10c). This suggests that substrate-protein interactions are tight at C-2 and there is not much space for chemical adjustments. This might be a consequence of the disturbed hydrogen-bonding with the asparagine and histidine moiety close to the 2-OH and suggests properties of 2-OH as both $\mathrm{H}$-bond donor and acceptor. Deoxygenation at C-4 is tolerated and leads to a slight increase in affinity which suggest that hydrogen bonding is not crucial at this position. In contrast to C-3 fluorination, deoxygenation leads to a dramatic loss of affinity. This is no surprise as previous study have determined $\mathrm{C}-3 \mathrm{H}$-bonding with glutamic acid E102 in which O-3 acts as donor. This is further confirmed as methyl, benzyl substitution at C-3 results in a loss up to 60-fold in affinity (Fig. 10e). Furthermore, mechanistic studies by Wright and coworkers have confirmed the involvement of $\mathrm{O}-3$ in $\mathrm{CH} / \pi$-interactions by mutation of "stacking" residue Y290 that causes severe loss of sugar affinity [94]. Critically, O-1 seems to have the most space, and can tolerate various groups such as methyl, phenyl, and naphthyl without a significant loss of affinity. Surprisingly, indican gives a tenfold improvement in affinity though it is transport is only at $14 \%$ of the maximal rate of $\alpha$-methoxy glucose [103]. It is also worthwhile to mention that the transporter has a preference for $\beta$-substitution as phenyl $\alpha$-D-glucose is not a substrate for the transporter although a small $\alpha$-linked moiety such as a methyl group is accepted. Finally, the endocyclic oxygen showed tolerance for its thio derivative (only a sixfold decrease). However, replacement by other heteroatoms as carbon (myo-inositol) or nitrogen (1-deoxynojirimycin) disturb crucial interactions so a sharp decrease in affinity is observed. Apart from interactions of the hydroxyl-groups, it is hypothesized that additional affinity is obtained by hydrophobic stacking interactions between the axial hydrogens and aromatic residues [13]. The information obtained from these studies are of importance regarding rational design and synthesis in targeting SGLT1 and suggest that chemical modification of C-1, C-4 and C-6 has the most potential.

\section{Carbohydrate transport by GLUT5}

GLUT5 was first isolated in 1990 by Bell and coworkers [104] and in 1992 confirmed as the major intestinal D-fructose transporter [17]. GLUT5 is also expressed in the kidney, sceletal muscle and adipose tissue (Table 1). GLUT5 is involved in the passive transport and, unlike SGLT1 [105], is $\mathrm{pH}$ and sodium independent [18]. The natural substrate D-fructose has a reported $K_{\mathrm{m}}$ of 6 [17]-15 $\mathrm{mM}$ [18]. Recent studies have shown that the top $10 \%$ of the population is now consuming about $75 \mathrm{~g}$ of fructose per day which, in 
(a) Natural substrates

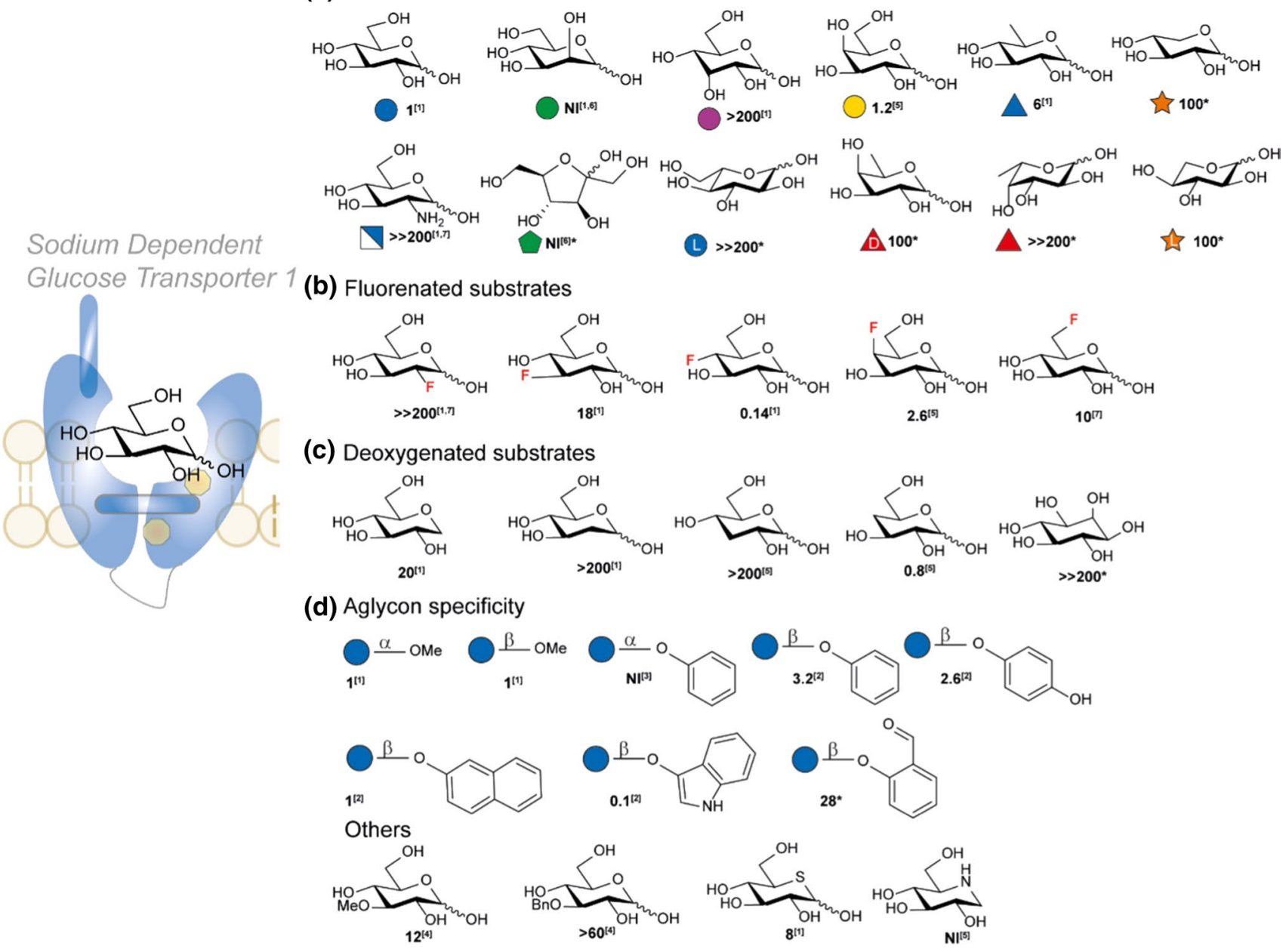

Fig. 10 Relative Substrate Affinity of hSGLT1 [93] grouped according to chemical substitution in natural substrates (a), fluorinated substrates (b), deoxygenated substrates (c), glycosylation (d) and other substitutions (e). $K_{0.5}$ values were obtained using a two-electrode voltage clamp method on Xenopus laevis oocytes. $I_{\max }$ in the substrates transported equalled $\sim 83 \%$ of the $I_{\max }$ of methyl $\alpha$-glucose. All

combination with the fructose released from sucrose by SI, requires high expression of GLUT5 [106]. The expression of GLUT5 is substrate dependent and is regulated on a transcriptional level [107]. Low expression of GLUT5, as is present in infants and young children, shows a higher chance of fructose malabsorption [108]. However, intestinal fructose malabsorption in adults was not associated with mRNA or protein levels of GLUT5 and the underlying cause is still unknown [109]. To maintain a gradient after consumption, $\mathrm{D}$-fructose is rapidly converted to fructose-1-phosphate by ketohexokinase which is expressed in the enterocytes of the ileum [110]. Determining the $K_{\mathrm{m}}$ value of the transporter is challenging, since oocyte voltage-clamp measurements cannot be performed. To study the transport, researcher have to rely on radio-isotope labelling, or more laborious methods. This is why most SAR-studies report a $K_{\mathrm{i}}$ instead. values reported are relative to the $K_{\mathrm{m}}$ of methyl $\alpha$-glucose $(0.5 \mathrm{mM})$. References used: ref 1 [13], ref 2 [97], ref 3 [98], ref 4 (or reported herein as unpublished data) [99], ref 5 [100], ref 6 [101], ref 7 (reported as unpublished data) [93]. The O-1 interaction could not be modelled. ${ }^{*} K_{\mathrm{m}}$ 's of rabbit SGLT1 (rbSGLT1) [102]

In addition to challenging measurements, D-fructose is present under physiological conditions as both furanose (30\%) and pyranose (70\%) which may complicate exact affinity determination further. Interestingly, D-fructose seems to bind GLUT5 mainly in the furanose form [18] which suggest a close cooperation between sucrase isomaltase and GLUT5. As the literature reports have been limited a substrate overview has been given mostly based on inhibitory constants (Fig. 12).

\section{Transport mechanism of GLUT5}

The exact mechanism of GLUT5 is still under investigation. The proposed mechanism consists of four major conformations comprising two open- and two bound states (Fig. 11). First, the outward open conformation binds the substrate and 
Fig. 11 Proposed mechanism of GLUT5 based on the model of facilitative membrane transporters

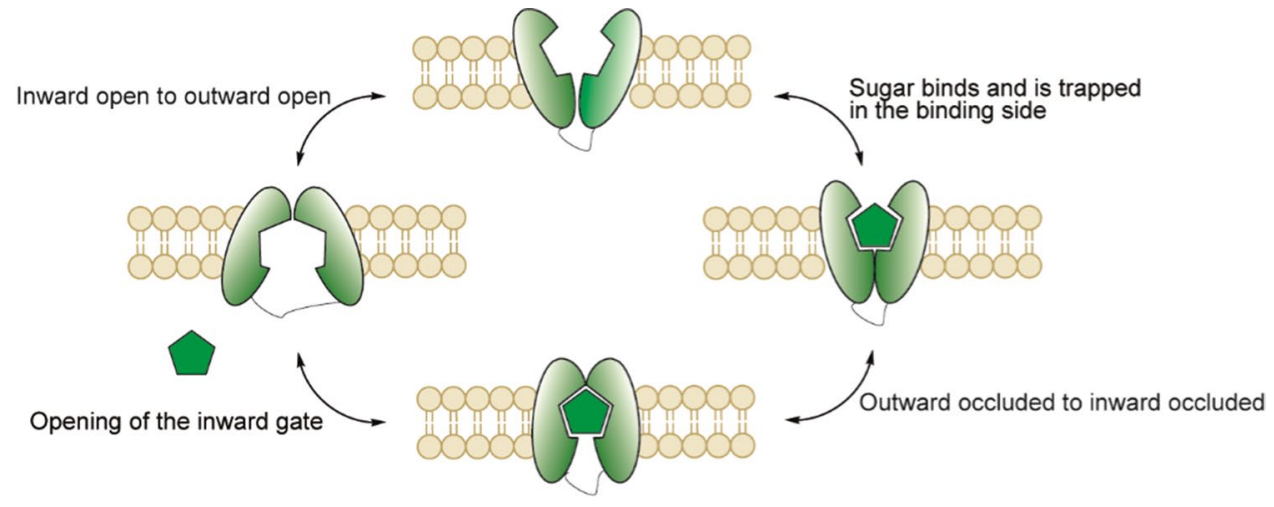

(a) Transport of Natural Substrates $\mathrm{K}_{\mathrm{m}}(\mathrm{mM})$

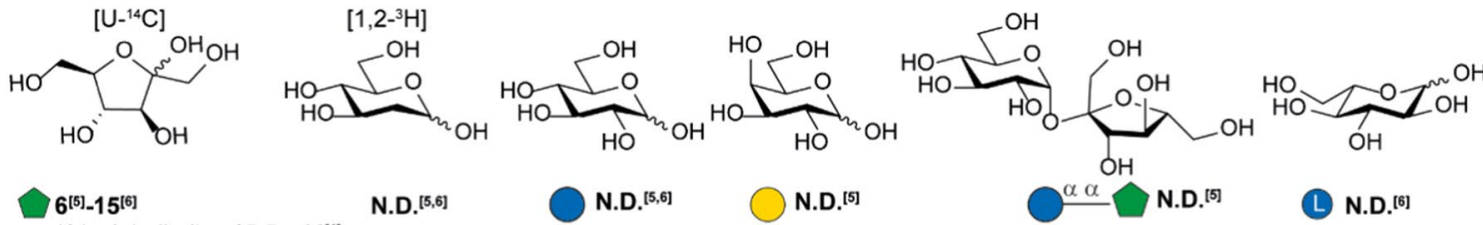

$K_{i}($ unlabelled $)=15.5 \mathrm{mM}^{[1]}$

N.D. ${ }^{[5,6]} N . D^{[5,6]} \bigcirc$ N.D. $^{[5]}$

(b) Affinity of Natural Substrates $K_{1}(\mathrm{mM})$<smiles>OC[C@H]1O[C@@](O)(CO)[C@@H](O)[C@H]1O</smiles><smiles>OC[C@H]1O[C@@](O)(CO)[C@@H](O)[C@@H]1O</smiles>

$59.4^{[1]}$<smiles>OC[C@]1(O)OC[C@@H](O)[C@@H](O)[C@H]1O</smiles>

(c) Affinity of 2,5-anhydro $\mathrm{K}_{i}(\mathrm{mM})$<smiles>C=CCNC[C@H]1O[C@H](CO)[C@@H](O)[C@H]1O</smiles>
GLUT5

(d) Glycon affinity monosubstitution $\mathrm{K}_{1}(\mathrm{mM})$<smiles>C=CCNC[C@]1(O)O[C@H](CO)[C@@H](O)[C@H]1O</smiles>

(e) Glycon affinity 2,3-tethered $\mathrm{K}_{1}(\mathrm{mM})$

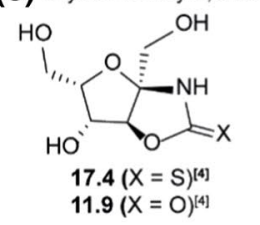

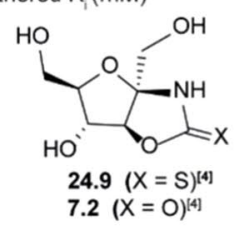<smiles>OCC1OC2NC(=S)OC2C1O</smiles><smiles>OCC1O[C@@H]2NC(=S)O[C@H]2C1O</smiles><smiles>OCC1O[C@@H]2NC(=S)O[C@H]2[C@H]1O</smiles><smiles>OC[C@H]1O[C@@H]2NC(=S)O[C@@H]2[C@H]1O</smiles>

(f) Aglycon Specificity $K_{i}(m M)$

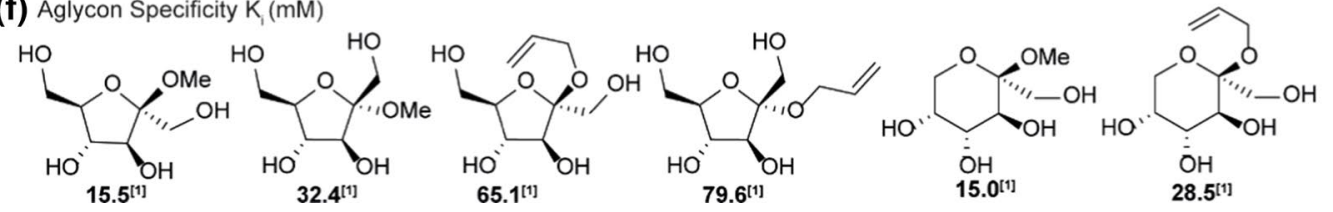

Fig. 12 SAR GLUT5. a Substrates $K_{\mathrm{i}}$ was determined relative to the inhibition of a radioactive tracer $\left[{ }^{14} \mathrm{C}-\mathrm{U}\right]-\mathrm{D}-\mathrm{fructose}$ [113]. References used: ref 1 [113], ref 2 [114], ref 3 [115], ref 4 [116], ref 5 [17], ref 6 [18]. N. D. not detected

forms the outward facing occluded state. Next, the outward facing occluded state changes to the inward facing occluded state. Finally, D-fructose releases and the GLUT5 finishes the cycle in the inward open conformation. Returning to the outward open conformation is speculated to be the rate limiting step in the general mechanism of these types of transporters 
[111]. Crystal structures of both the inward- and outward occluded states of GLUT5 derived from mammalian species Rattus norvegicus and Bos Taurus were reported in 2015 by Nomura et al. [112]. However, the details about the transitions between the four states are still under investigation.

\section{Substrate affinity of GLUT5 based on inhibition}

The most comprehensive studies about the substrate specificity of GLUT5 were performed by Holman and co-workers in the early 2000's. The method to determine selectivity is based on a CHO-cell line in which rat GLUT5 is expressed at high levels [117]. The $K_{\mathrm{i}}$ of the substrates are determined relative to the inhibition of the radioactive tracer $\left[{ }^{14} \mathrm{C}-\mathrm{U}\right]-\mathrm{D}-$ fructose [113]. Substrates tested range from epimers of D-fructose, mannitol derivatives $[113,115]$ to chemically modified D-fructose analogues at position $\mathrm{C}-1$ to C- 6 by alkylation [113], amination [115], C-5 thiolation [114] or C-2/C-3 tethering [116] (see Fig. 12b-e). Natural epimers of D-fructose at C-3 (D-psicose), C-4 (D-tagatose) and C-5 (L-sorbose) result in loss of affinity, most significant in case of L-sorbose which is mainly present in pyranose form. Binding and interaction of D-fructose with GLUT5 was studied by positional allylation (Fig. 12d). Allylation of $\mathrm{C}-1$ leads to a sharp decrease in affinity, whereas aminoallylation is better tolerated, suggesting there is a hydrogen bond donor interaction. This is also suggested from the trend observed in the locked C-2, C-3 oxazolidinone and oxazolidithione derivatives in which all aldopentoses show a sharp loss in affinity (Fig. 12e). Allylation at the C-3 position and $\mathrm{C}-4$ is unfavourable and leads to a loss in affinity which was already observed in case of epimers D-psicose and D-tagatose. Interestingly, FDA-approval of D-psicose (also referred to as D-allulose) in 2014 as safe by the FDA has sparked interest of the community as replacement of sucrose in the diet for obese and diabetic subjects. Critically, recent studies have showed that the substrate can be transported by GLUT5 $[118,119]$. Alkylation of C-5 gives the sharpest decrease in affinity, which may be the result of increasing ring size and limited chemical space. In addition, 5-OH substitution by a thiol also leads to a decrease in affinity suggesting hydrogen bond accepting interactions of the endocyclic oxygen with GLUT5. Interestingly, in contrast to C-1 to C-5, allylation of the $\mathrm{C}-6$ position is well tolerated suggesting there is some chemical space. This is also observed in the furanose locked C-2, C-3 oxazolidinone and oxazolidithione derivatives as both D-fructose as L-sorbose derivatives show good affinity.

Finally, substitution at C-2 (aglycon derivatives) shows that small substituents such as a methyl group are tolerated whereas allylation leads to a decrease in affinity. Surprisingly, the pyranose form is well tolerated. Again we note that all derivatives with an open anomeric centre can be present as furanose/pyranose mixture which makes it hard to determine the preferred substrate. A special case is C-2 deoxygenated analogue of D-fructose: 2,5-anhydro-D-mannitol (2,5-AM, Fig. 12c). The symmetrical sugar 2,5-AM has a good affinity for GLUT5 and is only present in furanose form. Critically, substitution at $\mathrm{C}-1$ results in increase in affinity. The decrease in complexity and potential conjugation site at $\mathrm{C}-1$ has been the main inspiration of 2,5-AM for GLUT5 specific probes and will be discussed below.

\section{GLUT5 affinity based on molecular probes}

Most GLUT5 transport studies utilized either radiolabelled $\left({ }^{14} \mathrm{C},{ }^{18} \mathrm{~F}\right)$ - or fluorescent probes (Fig. 13). First studies by Davidson in 1992 confirmed the transport of radiolabelled $\left[{ }^{14} \mathrm{C}\right]$-D-fructose by GLUT5 [17]. From a different perspective, Masuda and coworkers synthesized and evaluated $1-\left[{ }^{18} \mathrm{~F}\right]$-deoxy-D-fructose $\left(1-\left[{ }^{18} \mathrm{~F}\right]-\mathrm{FDF}\right)$ as a metabolic analogue of 2-[ $\left[{ }^{18} \mathrm{~F}\right]-\mathrm{FDG}[120]$. Though they noticed initial high uptake in GLUT5 expressing organs kidney liver and small intestine, the probe had no features of metabolic trapping by phosphorylation and was discarded as suitable PET-tracer. Inspired by the tolerance for C- 6 modification in Holman studies, Trayner et al. synthesized non-radiolabeled 6-deoxy-6-fluoro-D-fructose (6-FDF) as potential PET-tracer in breast cancer tissue [122]. 6-FDF showed inhibition of D-fructose transport mediated by GLUT2 and GLUT5. More important, the radiolabelled variant $\left[1-{ }^{14} \mathrm{C}\right]-6$-FDF showed accumulation in breast cancer cells with a two-fold increase over $\left[\mathrm{U}_{-}{ }^{14} \mathrm{C}\right]-\mathrm{D}-$ fructose. Transport of $\left[1-{ }^{14} \mathrm{C}\right]-6$-FDF was not affected by GLUT2 inhibitor cytochalasin B suggesting the majority of uptake taking place via GLUT5. A follow-up study by Cheeseman and coworkers with 6- $\left[{ }^{18} \mathrm{~F}\right]$-FDF again showed C-1 phosphorylation by recombinant KHK which supports metabolic trapping of 6-FDF [129]. In contrast, incubation with recombinant human hexokinase-II did not result in phosphorylation since the 6 position is blocked by fluorination. Interestingly, the uptake of $6-\left[{ }^{18} \mathrm{~F}\right]-\mathrm{FDF}$ was highly dependent on the cell line as a much lower accumulation was observed in MCF-7 cells than EMT-6. Comparison with $2-\left[{ }^{18} \mathrm{~F}\right]-\mathrm{FDG}$ showed no improvement on the latter. Next, also inspired by the trends Holman observed, Niu et al. explored radiolabelling of 2,5-anhydro-D-mannitol with the synthesis of $1-\left[{ }^{18} \mathrm{~F}-\right]$-anhydro-D-mannitol (1-[ $\left.\left.{ }^{18} \mathrm{~F}-\right]-D A M\right)$ [123]. 2,5-anhydro-D-mannitol has the advantage of being symmetrical and eliminates the possibility for furanose to pyranose interconversion thereby reducing the complexity of substrate studies. The compound was evaluated in a MCF-7 rabbit model which showed only a slight increase compared to normal breast tissue. High accumulation was observed in the liver (fructokinase-rich), kidney and bladder conform with the excretion pathway of 2,5-AM. 1- $\left[{ }^{18} \mathrm{~F}-\right]-\mathrm{DAM}$ was also used in a study by Soueidan et al. in addition to 3-deoxy-3-fluoro-D-fructose $\left(3-\left[1-{ }^{14} \mathrm{C}\right]-\mathrm{FDF}\right)$ with the latter 
existed mainly in pyranose form [124]. Both analogues were readily taken up in MCF-7 breast cancer cell lines with low $\mathrm{IC}_{50}$ values compared of 3.96 and $2.37 \mu \mathrm{M}$, respectively against $100 \mu \mathrm{M}\left[{ }^{14} \mathrm{C}\right]$-D-fructose. In a recent study by Wuest and coworkers, fructose PET radiotracers 1-FDF, 6-FDF and 1-FDAM were compared with 2-FDG and 6-FDG in murine BC model EMT-6 [130]. In the data presented all D-fructose derivatives were linked with GLUT5 protein levels in tissue. 6-FDF was found to give the highest tumor $v s$ muscle contrast among the fructose derivatives, however all showed washout of the tumor due to absence of metabolic trapping by hexokinase II. Involvement of GLUT2 was speculated as EMT-6 have a low GLUT5 expression, marking 6-FDF as a substrate for both transporters. Though the application of D-fructose as PET-radiotracer might be not as suited as 2-FDG, the trends observed clearly show that C-6 fluorinated substrates are accepted as GLUT5 substrates and are less prone to metabolic trapping.

Holman and coworkers reported the first GLUT5 specific photo labelled fructose substrate in 2002 which was introduced at the C-6 position of 2,5-anhydro-D-mannitol. Their probe was reported to show a tenfold affinity over D-fructose [115]. In contrast to the mannitol derivatives, Gambhir and coworkers synthesized two fructose derivatives to Cy5.5 and NBD via the $\mathrm{C}-1$ amine (NBDF). The uptake was assessed in MCF7 breast cancer cells with both probes showing good uptake. Interestingly, close comparison to cells lacking the GLUT5 still showed uptake of the Cy5.5 conjugate, suggesting GLUT5 independent uptake. The NBD dye did show GLUT5 dependent uptake underlining the possible interference of large fluorophores on the substrate recognition of smaller molecules [125, 131]. It must be noted that this result is still under debate as NBDF is sensitive to both D-glucose and D-fructose in uptake studies [125] and was also found to be inhibited by D-glucosamine [126], a substrate for GLUT2. Tanasova et al. continued on 2,5-AM derived fluorescent probes and synthesized NBD derived 1-amino-2,5-AM conjugate (NBDM) and evaluated the probe in MCF-7 cells, NBDF and NBDG were added for comparison [126]. NBDM was transported twice as efficiently compared to fructose GLUT5. In addition, fructose preconditioning (fructose rich-medium) resulted in twice as much NBDM transport. NBDM transport was not inhibited by D-glucose and D-glucosamine, pointing towards GLUT5 mediated transport. An interesting SAR was performed by Soueidan et al. based on the synthesized C-6 NBD conjugates of both D-fructose (6-NBDF) and the C-3 (6-NBDP), C-4 (NBDT) and the C-5 (6-NBDS) epimers [127]. 6-NBDF showed rapid take up into MCF-7 and EMT-6 cell lines. Surprisingly, epimers 6-NBDP, 6-NBDT and 6-NBDS showed uptake via GLUT1 instead. This confirms again the hypothesis of Holman that modifications at C-3, C-4 and C-5 are poorly tolerated. In a follow-up study, this strategy was also applied to 2,5-AM and the influence of modification at the $\mathrm{C}-3$ position on D-glucose and D-fructose uptake in EMT-6 cells was studied [121]. H-bond donation was found as requirement as C-3 for interaction with GLUT5. A C-3 NBD derivative of fructose was evaluated for transport in cells and major transport was found via GLUT5 although a minor drop in uptake in presence of Cytochalasin B (GLUT1 inhibitor) could not exclude transport by GLUT1. A $K_{\mathrm{m}}$ in Xenopus laevis oocytes was found to be $1.2 \mathrm{mM}$, significantly lower than D-fructose. This suggest great promise for application of C-3 derived fructose conjugates in cellular uptake by GLUT5 as long as a spacer is taken with hydrogen bond donating capabilities. Finally, a new class of fluorescent probes based on C-6 coumarin substituted 2,5-AM conjugates was evaluated as application for the analysis of fructose uptake [132]. Electron withdrawing groups at the coumarin appeared to positively influence binding strength as uptake rates. Conjugate ManCou1 was reported to have a 156-fold higher affinity than D-fructose. Two of the conjugates were also tested for their potential as

(a) Radiolabelled probes

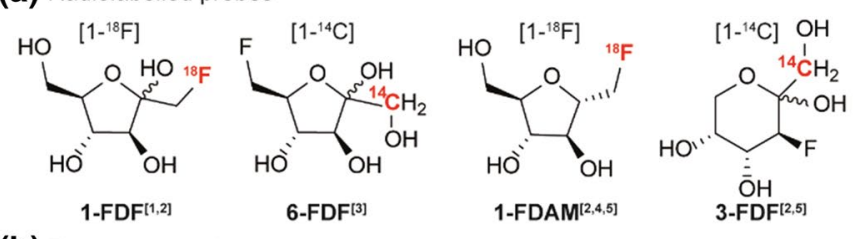

(b) Fluorescent probes

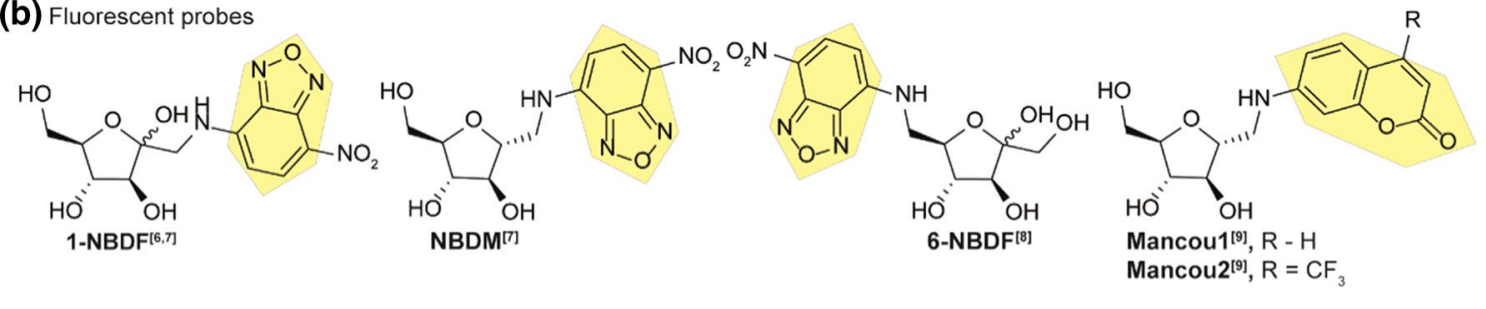

Fig. 13 Radiolabelled (a) and fluorescent probes (b) used in GLUT5 mediated uptake studies. References used: ref 1 [120], ref 2 [121], ref 3 [122], ref 4 [123], ref 5 [124], ref 6 [125], ref 7 [126], ref 8 [127], ref 9 [128] 
for rapid detection in breast cancer models [128]. A significant difference was found in the cancerous cells MCF-7 and MCF10AneoT compared to normal breast cells MCF10A underlining their potential for rapid on-site high-throughput diagnostics.

\section{Basolateral transport of carbohydrates}

After entering the enterocyte via the apical membrane, the nutritional sugars have to translocate to and cross the basolateral membrane to enter the bloodstream. The classical model describing intestinal sugar transport depicts GLUT2 as the main trans basolateral pathway that facilitates basolateral carbohydrate transport. Interestingly, the exact role of GLUT2 as sole pathway has been under debate [133]. GLUT2 null mice showed normal transport rates of glucose appearance after oral administration despite lacking GLUT2 expression in the small intestine [134]. In addition, studies using an isolated intestinal perfusion model without GLUT2 observed normal glucose transport rates, even under accelerated apical uptake [135]. A different pathway was proposed involving glucose-6-phosphate translocase, a protein transporting glucose-6-phosphate to the lumen of the endoplasmic reticulum. Inhibition of glucose-6-phosphate translocase by S4048 showed decreased glucose release in GLUT2 $2^{-/-}$mice but not in the wild type. Interestingly, 3-O-methyl glucose, a substrate for both SGLT1 and GLUT2 which is not phosphorylated, was not transported in GLUT2 $^{-1-}$. These findings suggest that an alternative pathway based on the accumulation of glucose in the endoplasmic reticulum and subsequent membrane trafficking.

\section{Carbohydrate transport by GLUT2}

GLUT2 (SLCA2) is a facilitative glucose transporter, mainly expressed in the liver, intestine, kidney and pancreatic betacells [136, 137]. Its function involves: glucose- and fructose uptake [138] and release in hepatocytes, glucose and galactose transport over the basolateral membrane in intestinal cells. Furthermore, GLUT2 plays a critical role in the reabsorption of glucose on the basolateral membrane of the kidney. Defects in the GLUT2 gene cause the FanconiBickel syndrome, leading to pathogenic processes such as hepatomegaly and growth retardation [139]. The affinity for glucose is much lower than SGLT1 (17-20 mM compared to $0.5 \mathrm{mM}$ ) but is compensated by a high transport capacity [140]. GLUT2 is presumed to act via the general mechanism based on the model of facilitative transporters (Fig. 14). Critically, the role of GLUT2 in the small intestines has been under debate after studies showed translocation of GLUT2 from the apical membrane to the apical membrane at high glucose concentrations [141, 142]. This may suggest a role in D-glucose uptake under certain conditions and would make GLUT2 a potential target transporter for uptake of exogeneous conjugates. Studies in GLUT2 knock out mice [134] and an isolated intestine perfusion system [135] showed normal glucose uptake indicating GLUT2 as not essential for uptake in the small intestine. A comprehensive study using both SGLT1 and GLUT2 knockouts unequivocally identified SGLT1 as the prime glucose transporter and did not find any evidence for GLUT2 playing a role in glucose uptake at the apical side [86]. This debate was not limited to GLUT2 mediated glucose uptake but also for D-fructose uptake as GLUT5 surrogate [143]. Wild mice fed on a high fructose diet showed a fivefold increase of fructose uptake and only twofold in GLUT2 ${ }^{-/-}$mice suggesting a significant role of GLUT2 in high fructose diets. In contrast, mice with GLUT5 $^{-1-}$ showed malabsorption and PKC $\beta$-II-mediated GLUT2 insertion did not lead to rescue. Additionally, apical perfusion with high-fructose solutions in neonatal rats increased solely GLUT5 expression [144, 145]. As the exact nature of GLUT2 in the apical membrane remains unclear we will only focus on the better defined role of GLUT2 in basolateral transport.

\section{GLUT2 substrate affinity}

Similar to GLUT5, no crystal structure of GLUT2 is available. SAR studies in the early 90 's by Gould and co-workers revealed an interesting trend in GLUT2 substrate preference.
Fig. 14 Proposed mechanism of GLUT2 based on the model of facilitative membrane transporters

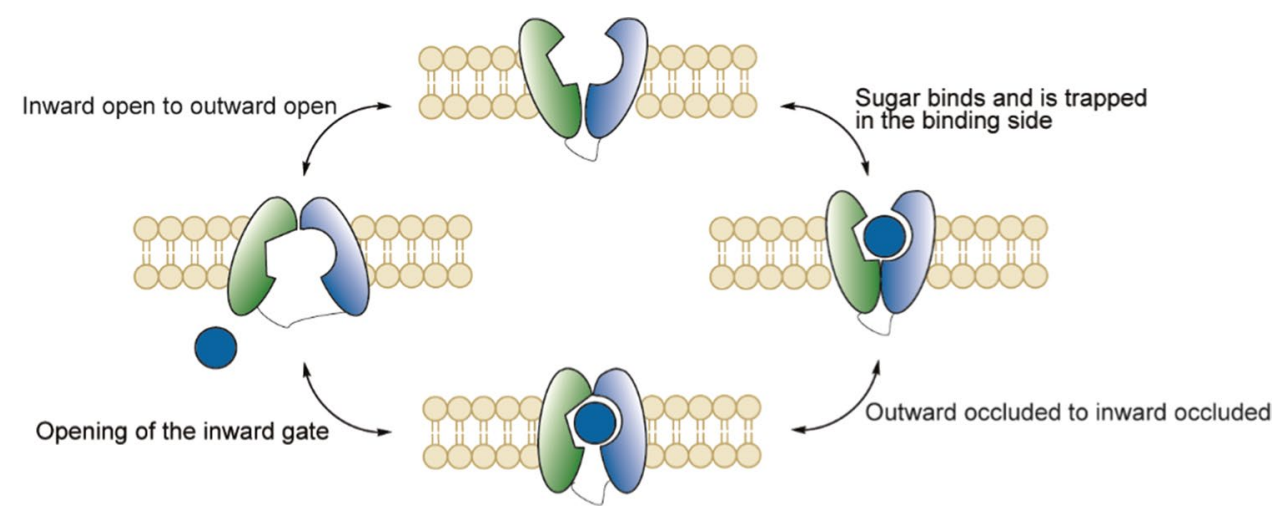


(a) Substrates Radioisotopes $\left(\mathrm{K}_{\mathrm{m}}\right.$ in $\left.\mathrm{mM}\right)$

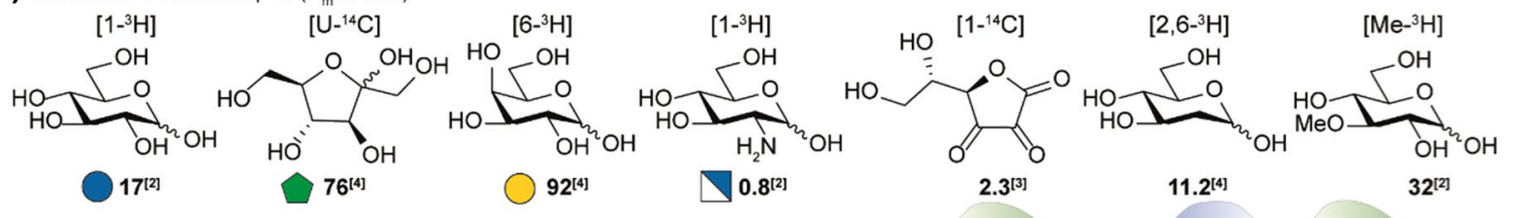

(b) Natural substrates (relative transport of $\left[2,6-{ }^{-3}\right]-2$-deoxy-glucose ${ }^{[1]}$

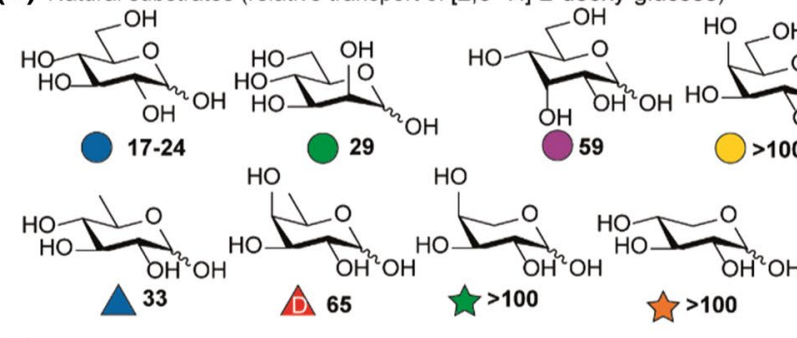

(c) Synthetic substrates (relative transport of $\left[2,6-{ }^{3} \mathrm{H}\right]-2$-deoxy-glucose) ${ }^{[1]}$

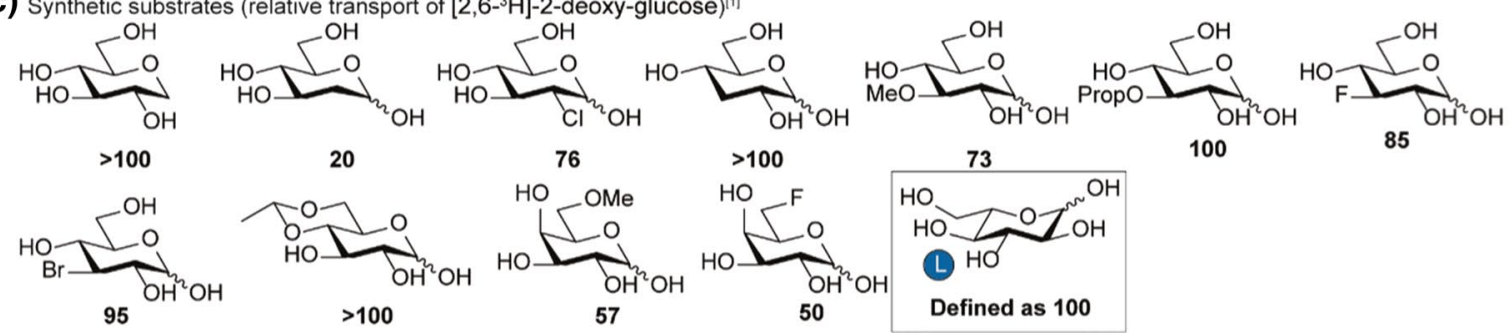

Fig. 15 SAR GLUT2. a $\mathrm{K}_{\mathrm{m}}$ of GLUT2 substrates based on radioisotope-labelling. b Resulting relative transport of $\left[2,6-{ }^{3} \mathrm{H}\right]-2$-deoxyglucose $(100 \mu \mathrm{M})$ against $10 \mathrm{mM}$ of the competing sugar measured in oocytes [16]. Rates are expressed as the percentage of transport of

In a comparative study between GLUT2, -3 and -4 , various carbohydrate substrates were co-administered in oocytes and their influence on the transport of radio-labelled $\left[2,6-{ }^{3} \mathrm{H}\right]-$ 2-deoxyglucose $\left(K_{\mathrm{m}}=11.2\right)$ was studied (Fig. $\left.15 \mathrm{~b}, \mathrm{c}\right)$. L-Glucose did not inhibit uptake of the radioactive tracer and the uptake observed was used as reference (defined as 100) [16]. D-glucose showed a high inhibition of transport, additional studies using a radioactive labelling of glucose later showed a $K_{\mathrm{m}}$ of $\sim 17 \mathrm{mM}$ [14] which is relatively high compared to other GLUT transporters. Addition of 1-deoxy-D-glucose did not alter the uptake of the radioactive tracer. Surprisingly, C-2 derivatives 2-DG and D-mannose show high affinity for GLUT2 whereas chlorination is less well tolerated. $2-\left[{ }^{34 \mathrm{~m}} \mathrm{Cl}\right]-2$-deoxy-D-glucose was later evaluated in an animal PET-study and did not show accumulation in GLUT2 rich tissue, instead rapid excretion was observed [147]. The high affinity observed at C-2 was later confirmed in transport studies which showed an exceptionally high affinity of GLUT2 for D-glucosamine (Fig. $15 \mathrm{a}, K_{\mathrm{m}}=0.8 \mathrm{mM}$ ) [14]. The $V_{\max }$ reported $(3610 \mathrm{pmol} / \mathrm{oocyte} / \mathrm{h}$ ) was only three-fold lower compared to D-glucose $(12,000 \mathrm{pmol} / \mathrm{oocyte} / \mathrm{h})$. The sharp decrease of inhibition observed with deoxygenation at the $\mathrm{C}-3$ position suggest involvement in hydrogen bonding. Methylation is tolerated which is also reflected by a $K_{\mathrm{m}}$ of control compound $10 \mathrm{mM}$ L-glucose (set as 100). c C-6 derivatives where tested by incubation of $50 \mathrm{mM}$ substrate. References used: ref. 1 [16], ref. 2 [14], ref 3 [146], ref 4 [15]

$32 \mathrm{mM}$ observed in radiolabelled 3-OMG though alkylation with longer alkyl groups is not tolerated. Interestingly, D-allose is a relatively good inhibitor which is in contrast to related transporters GLUT1,-3 and -4. Substitution of C-4 shows no sign of improved recognition by the transporter, this is in sharp contrast to SGLT1 which has a tolerance for C-4. Hence transport of D-galactose by GLUT2 has a high $K_{\mathrm{m}}$. Interestingly, C-6 derivatives still show inhibition with 6-deoxy sugar D-quinovose as the best inhibitor. Though no transport studies have been performed, this suggest that C-6 derivatives are an interesting target for GLUT2 specific probes. As previously mentioned, GLUT2 is also able to transport D-fructose with a relative affinity of $76 \mathrm{mM}$. The unique ability to transport C-2 derivatives of D-glucose is most dramatically reflected by streptozotocin toxicity in the islet $\beta$-cells [148]. This effect has been succesfully employed in combination with chemotherapy in the treatment of metastatic pancreatic neuroendocrine tumors $[149,150]$. Other compounds as fructosazine (evaluated in Caco-2) [151] and glycosylated anthocyanins (evaluated in Caco-2) [152] and small glucosamine-conjugated glycopeptides [153] also showed characteristics of GLUT2 mediated uptake though no GLUT2 specific kinetic experiments have been performed. A 6-O-conjugated azomycin derivative did show a 
GLUT2 dependent toxicity [154]. In contrast to SGLT1 and GLUT5, GLUT2 thusfar has no specific substrate for PETstudies though $2-\left[{ }^{18} \mathrm{~F}\right]-\mathrm{DG}$ is proposed to be transporter by GLUT transporters including GLUT2 [155] (see Fig. 16).

\section{Relevance and conclusion}

The wide variety of carbohydrate digestive processes involved in the GI-tract require a broad knowledge for scientists to exploit for diagnostics and therapeutics. To highlight some examples, the GI-tract can already be targeted to influence carbohydrate homeostasis for instance by acarbose (Fig. 16). Acarbose is an antidiabetic drug used to treat diabetes mellitus type 2 by inhibiting $\alpha$-glycosidase activity in MGAM and SI. This blocks the enzymatic hydrolysis of starch oligo- and di-saccharides to monosaccharides thus reducing blood sugar level. In contrast, transport proteins like SGLT1 are unaffected so monosaccharide transport can still take place. In addition, patients can eat controlled amounts of pure glucose to prevent hypoglycaemia.

In the field of diagnostics small differences in preferred affinity can be used to discriminate between SGLTs and GLUTs. Transporters like SGLT1 allow C-4 modification of substrates whereas $\mathrm{C}-2$ modification leads to loss in affinity. The opposite is applicable for GLUT transporters like GLUT2. This is most clearly demonstrated by the use of 2- $\left[{ }^{18} \mathrm{~F}\right]-\mathrm{DG}$ as GLUT specific PET-tracer $[155,156]$ and $\alpha$-methoxy-4- $\left[{ }^{18} \mathrm{~F}\right]$-D-glucose SGLT-selective PET-tracer [98] and allows the latter to study SGLT-rich regions such as the kidney, skeletal muscle, heart and liver [93]. Importantly, glycosides of drugs may be useful to improve intestinal absorption, targeting to the colon, reduction of gastrointestinal disturbances and to improve solubility.

\section{Improved intestinal absorption}

It has been extensively reported that absorption of quercetin from its glucosides is improved compared to absorption of quercetin itself (see Fig. 7a for structures). The intact glucoside conjugates were not observed on the serosal side of the intestinal membrane, suggesting that hydrolysis is performed on the outside of the enterocytes by LPH or on the inside by CBG. Subsequent studies revealed that the hydrolysis rate of quercetin-4'-glucoside is 10 times higher than the corresponding quercetin-3-glucoside [157]. It was found that SGLT1 plays a role in the hydrolysis kinetics of the 4'-glucoside as inhibition of the transporter by phloridzin strongly reduces the hydrolysis rate. In contrast, hydrolysis of the 3-glucoside was not affected by phlorizin. Evidently the mechanism of absorption of quercitin from its quercetin4'-glucoside involves both an interaction with SGLT1 and luminal hydrolysis by LPH, whereas quercetin from its quercetin-3-glucoside appears to be absorbed only following hydrolysis by LPH. Taken together, the results suggest that hydrolysis of the glucosides is required before absorption of quercetin can occur. Apparently, this process brings quercetin in close proximity to the intestinal membrane which facilitates its uptake. In is unclear whether this mechanism holds true for other drug glycosides. Very few results have been disclosed on the improvement of oral bioavailability by glycoside prodrugs of medication. The use of prednisolone$21-O-\beta$-D-glucoside was reported to produce a two-fold increase of oral bioavailability with respect to prednisolone [158]. Another study disclosed the improved bioavailability of glycuronamide and glycoside prodrugs of fluoxetine [159]. Hydrophilic transportable $N$-linked glycosyl dopaminergic compounds were reported to show improved oral bioavailability and brain penetration [160]. Finally, glycosyl carbamoylalkylidene prodrugs were reported to provide enhanced oral bioavailability of drugs [161].

\section{Targeting to the colon}

Dexamethasone 21- $\beta$-D-glucoside and prednisolone 21- $\beta$-Dglucoside were prepared as prodrugs and were investigated for their prospects in treating inflammatory bowel disease [162]. Both glucosides were found to reach the rat lower intestine where they were rapidly hydrolysed, releasing the free steroids. Delivery of dexamethasone via its glucoside to the colon was more specific than that of prednisolone, delivered via its glucoside: nearly $60 \%$ of an oral dose of dexamethasone glucoside reached the cecum, whereas less than $15 \%$ of prednisolone glucoside reached the cecum. When
Fig. 16 Glycoside derivatives exploited for diagnostics and therapeutics

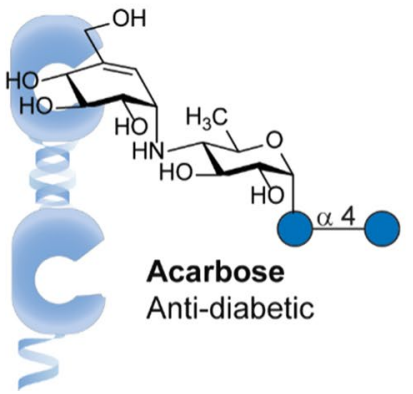

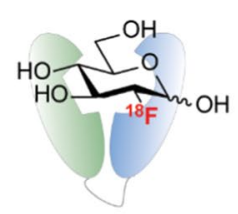

2-[18 F]-DG GLUT specific PET-probe

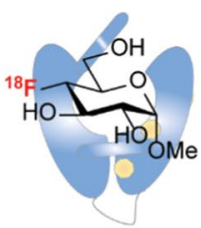

$\alpha-M e-4-\left[{ }^{18} \mathrm{~F}\right]-\mathrm{DG}$ SGLT specific PET-probe 
the free steroids were administered orally, they were almost exclusively absorbed in the small intestine: less than $1 \%$ of an oral dose of each reached the cecum. In another study it was found that oral administration of dexamethasone- $\beta$-Dglucoside led to reduced gross pathological effects (fluid cecal contents, redness, edema, ulcerations) and a significantly lower histopathological score relative to dexamethasone, which was ineffective at controlling the inflammatory response relative to control animals [163]. In contrast to the results with dexamethasone glucoside, the use of prednisolone-21- $O-\beta$-D-glucoside was reported to produce a two-fold increase of oral bioavailability with respect to prednisolone [158]. Similarly, $\beta$-D-glucoside and $\beta$-D-galactoside conjugates of 5-aminosalicylic acid were found to be useful to target 5-aminosalicylic acid to the colon. The glycoside was hydrolysed by glycosidase activity from bacterial intestinal flora [164].

\section{Reduction gastrointestinal disturbances}

Sugar prodrugs of a great number of nonsteroidal antiinflammatory drugs (NSAIDs) have been designed and synthesized. When administered orally, such prodrugs are more soluble than their parent NSAIDs, thus causing less stomach irritation. The rationale behind these sugar prodrugs is that sugar conjugates are expected to exhibit reduced adverse effects particularly in the gastrointestinal (GI) tract. Glycosylated acetaminophen prodrugs were reported to show a higher solubility [165]. An orally administrable prodrug of ketorolac was disclosed as a reversible conjugate with to D-galactose (ketogal) [166]. This prodrug was able to maintain the anti-inflammatory and the analgesic activity of the drug without giving rise to gastric ulcer formation. Ester prodrugs of ibuprofen were synthesized using $\alpha$-methyl, ethyl and propyl glucopyranoside as promoieties and were tested for their anti-inflammatory, analgesic and ulcerogenic activities [167]. On oral administration the prodrugs did elicit a pharmacological profile quite similar to that of ibuprofen, but, unlike this drug, they displayed reduced gastric ulceration.

Summarized, as the principle challenges in drug administration are the solubility of the active-drug $[168,169]$ and the permeability of the drug over the intestinal membrane, the structural knowledge of substrates glycoside transporters and hydrolases can be of important advantage to tackle these challenges. We aim that this review focussed on molecular structure, represents a solid simplified bases to start from and to fuel the research in the area of therapeutics and diagnostics.

Funding H. Elferink is supported by a NWO-LIFT (731.015.420) grant awarded to Dr. T. J. Boltje.
Open Access This article is licensed under a Creative Commons Attribution 4.0 International License, which permits use, sharing, adaptation, distribution and reproduction in any medium or format, as long as you give appropriate credit to the original author(s) and the source, provide a link to the Creative Commons licence, and indicate if changes were made. The images or other third party material in this article are included in the article's Creative Commons licence, unless indicated otherwise in a credit line to the material. If material is not included in the article's Creative Commons licence and your intended use is not permitted by statutory regulation or exceeds the permitted use, you will need to obtain permission directly from the copyright holder. To view a copy of this licence, visit http://creativecommons.org/licenses/by/4.0/.

\section{References}

1. Wright EM, Martín MnG, Turk E (2003) Intestinal absorption in health and disease-sugars. Best Pract Res Clin Gastroenterol 17(6):943-956. https://doi.org/10.1016/S1521 $-6918(03) 00107-0$

2. Butterworth PJ, Warren FJ, Ellis PR (2011) Human $\alpha$-amylase and starch digestion: an interesting marriage. Starch 63(7):395-405. https://doi.org/10.1002/star.201000150

3. Fogel MR, Gray GM (1973) Starch hydrolysis in man: an intraluminal process not requiring membrane digestion. $\mathrm{J}$ Appl Physiol 35(2):263-267. https://doi.org/10.1152/jappl .1973 .35 .2 .263

4. Ferraris RP, Diamond J (1997) Regulation of intestinal sugar transport. Physiol Rev 77(1):257-302. https://doi.org/10.1152/ physrev.1997.77.1.257

5. Hammond KA (1997) Adaptation of the maternal intestine during lactation. J Mammary Gland Biol 2(3):243-252. https:// doi.org/10.1023/A:1026332304435

6. Thiesen A, Drozdowski L, Iordache C, Neo CC, Woudstra TD, Xenodemetropoulos T, Keelan M, Clandinin MT, Thomson ABR, Wild G (2003) Adaptation following intestinal resection: mechanisms and signals. Best Pract Res Clin Gastroenterol 17(6):981-995. https://doi.org/10.1016/S1521-6918(03)00097-0

7. Ugidos-Rodríguez S, Matallana-González MC, Sánchez-Mata MC (2018) Lactose malabsorption and intolerance: a review. Food Funct 9(8):4056-4068. https://doi.org/10.1039/C8FO0 0555A

8. Ren LM, Qin XH, Cao XF, Wang LL, Bai F, Bai G, Shen YQ (2011) Structural insight into substrate specificity of human intestinal maltase-glucoamylase. Protein Cell 2(10):827-836. https://doi.org/10.1007/s13238-011-1105-3

9. Chaudet MM, Amiri M, Marth N, Naim HY (1863) Rose DR (2019) Phylogenetic analysis reveals key residues in substrate hydrolysis in the isomaltase domain of sucrase-isomaltase and its role in starch digestion. BBA Gen Subj 9:1410-1416. https ://doi.org/10.1016/j.bbagen.2019.06.011

10. Labat-Robert J, Baumann FC, Bar-Guilloux E, Robic D (1978) Comparative specificities of trehalases from various species. Comp Biochem Phys B 61(1):111-114. https://doi. org/10.1016/0305-0491(78)90225-0

11. Skovbjerg H, Sjostrom H, Noren O (1981) Purification and characterisation of amphiphilic lactase/phlorizin hydrolase from human small intestine. Eur J Biochem 114(3):653-661. https://doi.org/10.1111/j.1432-1033.1981.tb05193.x

12. Hayashi Y, Okino N, Kakuta Y, Shikanai T, Tani M, Narimatsu $\mathrm{H}$, Ito M (2007) Klotho-related protein is a novel cytosolic neutral $\beta$-glycosylceramidase. J Biol Chem 282(42):3088930900. https://doi.org/10.1074/jbc.M700832200

13. Díez-Sampedro A, Wright EM, Hirayama BA (2001) Residue 457 controls sugar binding and transport in the $\mathrm{Na}+$ /glucose 
cotransporter. J Biol Chem 276(52):49188-49194. https://doi. org/10.1074/jbc.M108286200

14. Uldry M, Ibberson M, Hosokawa M, Thorens B (2002) GLUT2 is a high affinity glucosamine transporter. FEBS Lett 524(13):199-203. https://doi.org/10.1016/s0014-5793(02)03058-2

15. Arbuckle MI, Kane S, Porter LM, Seatter MJ, Gould GW (1996) Structure-function analysis of liver-type (GLUT2) and brain-type (GLUT3) glucose transporters: expression of chimeric transporters in xenopus oocytes suggests an important role for putative transmembrane helix 7 in determining substrate selectivity. Biochemistry 35(51):16519-16527. https:// doi.org/10.1021/bi962210n

16. Colville CA, Seatter MJ, Jess TJ, Gould GW, Thomas HM (1993) Kinetic analysis of the liver-type (GLUT2) and braintype (GLUT3) glucose transporters in Xenopus oocytes: substrate specificities and effects of transport inhibitors. Biochem J 290(3):701-706

17. Burant CF, Takeda J, Brot-Laroche E, Bell GI, Davidson NO (1992) Fructose transporter in human spermatozoa and small intestine is GLUT5. J Biol Chem 267(21):14523-14526

18. Kane S, Seatter MJ, Gould GW (1997) Functional studies of human GLUT5: effect of $\mathrm{pH}$ on substrate selection and an analysis of substrate interactions. Biochem Bioph Res Commun 238(2):503-505. https://doi.org/10.1006/bbrc.1997.7204

19. Van Beers EH, Buller HA, Grand RJ, Einerhand AW, Dekker J (1995) Intestinal brush border glycohydrolases: structure, function, and development. Crit Rev Biochem Mol Biol 30(3):197262. https://doi.org/10.3109/10409239509085143

20. Lombard V, Golaconda Ramulu H, Drula E, Coutinho PM, Henrissat B (2014) The carbohydrate-active enzymes database (CAZy) in 2013. Nucleic Acids Res 42(D1):D490-D495. https ://doi.org/10.1093/nar/gkt1178

21. Davies G, Henrissat B (1995) Structures and mechanisms of glycosyl hydrolases. Structure 3(9):853-859. https://doi. org/10.1016/s0969-2126(01)00220-9

22. Kötzler MP, Hancock SM, Withers SG (2001) Glycosidases: functions, families and folds. eLS. https://doi.org/10.1002/97804 70015902.a0020548.pub2

23. Rye CS, Withers SG (2000) Glycosidase mechanisms. Curr Opin Chem Biol 4(5):573-580

24. Skovbjerg H (1981) Immunoelectrophoretic studies on human small intestinal brush border proteins-the longitudinal distribution of peptidases and disaccharidases. Clin Chim Acta 112(2):205-212

25. Koshland DE (1953) Stereochemistry and the mechanism of enzymatic reactions. Biol Rev 28(4):416-436. https://doi. org/10.1111/j.1469-185X.1953.tb01386.X

26. Ketudat Cairns JR, Esen A (2010) beta-Glucosidases. Cell Mol Life Sci 67(20):3389-3405. https://doi.org/10.1007/s0001 8-010-0399-2

27. Mori H, Lee JH, Okuyama M, Nishimoto M, Ohguchi M, Kim D, Kimura A, Chiba S (2009) Catalytic reaction mechanism based on alpha-secondary deuterium isotope effects in hydrolysis of trehalose by European honeybee trehalase. Biosci Biotechnol Biochem 73(11):2466-2473. https://doi.org/10.1271/bbb.90447

28. Davies GJ, Wilson KS, Henrissat B (1997) Nomenclature for sugar-binding subsites in glycosyl hydrolases. Biochem J 321(Pt 2):557-559

29. Semenza G (1986) Anchoring and biosynthesis of stalked brushborder membrane-proteins-glycosidases and peptidases of enterocytes and renal tubuli. Annu Rev Cell Biol 2:255-313. https://doi.org/10.1146/annurev.cb.02.110186.001351

30. Quezada-Calvillo R, Sim L, Ao Z, Hamaker BR, Quaroni A, Brayer GD, Sterchi EE, Robayo-Torres CC, Rose DR, Nichols BL (2008) Luminal starch substrate "brake" on maltase-glucoamylase activity is located within the glucoamylase subunit. J Nutr 138(4):685-692

31. Lebenthal E, Khin Maung U, Zheng B-Y, Lu R-B, Lerner A (1994) Small intestinal glucoamylase deficiency and starch malabsorption: a newly recognized alpha-glucosidase deficiency in children. J Pediatr 124(4):541-546. https://doi.org/10.1016/ S0022-3476(05)83131-2

32. Nichols BL, Avery SE, Karnsakul W, Jahoor F, Sen P, Swallow DM, Luginbuehl U, Hahn D, Sterchi EE (2002) Congenital maltase-glucoamylase deficiency associated with lactase and sucrase deficiencies. J Pediatr Gastroenterol Nutr 35(4):573-579

33. Sim L, Jayakanthan K, Mohan S, Nasi R, Johnston BD, Pinto BM, Rose DR (2010) New glucosidase inhibitors from an ayurvedic herbal treatment for type 2 diabetes: structures and inhibition of human intestinal maltase-glucoamylase with compounds from Salacia reticulata. Biochemistry 49(3):443-451. https://doi.org/10.1021/bi9016457

34. Sim L, Quezada-Calvillo R, Sterchi EE, Nichols BL, Rose DR (2008) Human intestinal maltase-glucoamylase: crystal structure of the N-terminal catalytic subunit and basis of inhibition and substrate specificity. J Mol Biol 375(3):782-792. https:// doi.org/10.1016/j.jmb.2007.10.069

35. Jones K, Sim L, Mohan S, Kumarasamy J, Liu H, Avery S, Naim HY, Quezada-Calvillo R, Nichols BL, Pinto BM, Rose DR (2011) Mapping the intestinal alpha-glucogenic enzyme specificities of starch digesting maltase-glucoamylase and sucrase-isomaltase. Bioorg Med Chem 19(13):3929-3934. https://doi.org/10.1016/j.bmc.2011.05.033

36. Lee B-H, Rose DR, Lin AH-M, Quezada-Calvillo R, Nichols BL, Hamaker BR (2016) Contribution of the individual small intestinal $\alpha$-glucosidases to digestion of unusual $\alpha$-linked glycemic disaccharides. J Agr Food Chem 64(33):6487-6494. https://doi.org/10.1021/acs.jafc.6b01816

37. Semenza G, Auricchio S, Mantei N (2014) Small-intestinal disaccharidases. In: Beaudet AL, Vogelstein B, Kinzler KW, et al. (eds) The online metabolic and molecular bases of inherited disease. The McGraw-Hill Companies, Inc., New York

38. Sorensen SH, Noren O, Sjostrom H, Danielsen EM (1982) Amphiphilic pig intestinal microvillus maltase/glucoamylase. Structure and specificity. Eur J Biochem 126(3):559-568

39. Taravel FR, Datema R, Woloszczuk W, Marshall JJ, Whelan WJ (1983) Purification and characterization of a pig intestinal alpha-limit dextrinase. Eur J Biochem 130(1):147-153

40. Galand G (1989) Brush border membrane sucrase-isomaltase, maltase-glucoamylase and trehalase in mammals. Comparative development, effects of glucocorticoids, molecular mechanisms, and phylogenetic implications. Comp Biochem Phys B 94(1):1-11

41. Kessler M, Acuto O, Storelli C, Murer H, Müller M, Semenza $G$ (1978) A modified procedure for the rapid preparation of efficiently transporting vesicles from small intestinal brush border membranes. Their use in investigating some properties of d-glucose and choline transport systems. BBA Biomembranes 506(1):136-154. https://doi.org/10.1016/0005-2736(78)90440 $-6$

42. Hauri H-P, Quaroni A, Isselbacher KJ (1979) Biogenesis of intestinal plasma membrane: posttranslational route and cleavage of sucrase-isomaltase. J Proc Natl Acad Sci 76(10):5183-5186. https://doi.org/10.1073/pnas.76.10.5183

43. Gericke B, Schecker N, Amiri M, Naim HY (2017) Structurefunction analysis of human sucrase-isomaltase identifies key residues required for catalytic activity. J Biol Chem 292(26):11070_ 11078. https://doi.org/10.1074/jbc.M117.791939

44. Treem WR (1995) Congenital sucrase-isomaltase. Deficiency 21(1):1-14 
45. Naim HY, Heine M, Zimmer K-P (2012) Congenital sucraseisomaltase deficiency: heterogeneity of inheritance trafficking, and function of an intestinal enzyme complex. J Pediatr Gastroenterol Nutr 55:S13-S20. https://doi.org/10.1097/01.mpg.00004 21402.57633.4b

46. Ishihara R, Taketani S, Sasai-Takedatsu M, Kino M, Tokunaga R, Kobayashi Y (1997) Molecular cloning, sequencing and expression of cDNA encoding human trehalase. Gene 202(1):69-74. https://doi.org/10.1016/S0378-1119(97)00455-1

47. Galand G (1984) Purification and characterization of kidney and intestinal brush-border membrane trehalases from the rabbit. Biochim Biophys Acta 789(1):10-19

48. Birch GG (1963) Trehaloses. Adv Carbohyd Chem 18:201-225

49. Robinson NL, Goldsworthy GJ (1977) Adipokinetic hormone and the regulation of carbohydrate and lipid metabolism in a working flight muscle preparation. J Insect Physiol 23(1):9-16

50. Clifford KH (1980) Stereochemistry of the hydrolysis of trehalose by the enzyme trehalase prepared from the flesh fly Sarcophaga barbata. Eur J Biochem 106(1):337-340

51. Gibson RP, Gloster TM, Roberts S, Warren RA, Storch de Gracia I, Garcia A, Chiara JL, Davies GJ (2007) Molecular basis for trehalase inhibition revealed by the structure of trehalase in complex with potent inhibitors. Angew Chem Int Ed Engl 46(22):4115-4119. https://doi.org/10.1002/anie.200604825

52. Bergoz R (1971) Trehalose malabsorption causing intolerance to mushrooms: report of a probable case. Gastroenterology 60(5):909-912. https://doi.org/10.1016/S0016-5085(71)80092 $-6$

53. Hehre EJ, Sawai T, Brewer CF, Nakano M, Kanda T (1982) Trehalase: stereocomplementary hydrolytic and glucosyl transfer reactions with alpha- and beta-D-glucosyl fluoride. Biochemistry 21(13):3090-3097

54. Nakano M, Sacktor B (1984) Renal trehalase: two subsites at the substrate-binding site. Biochim Biophys Acta 791(1):45-49

55. Elbein AD, Pan YT, Pastuszak I, Carroll D (2003) New insights on trehalose: a multifunctional molecule. Glycobiology 13(4):17R-27R. https://doi.org/10.1093/glycob/cwg047

56. Naim HY (2001) Molecular and cellular aspects and regulation of intestinal lactase-phlorizin hydrolase. Histol Histopathol 16(2):553-561

57. Amiri M, Diekmann L, Köckritz-Blickwede V, Naim HYJN (2015) The diverse forms of lactose intolerance and the putative linkage to several cancers. Nutrients 7(9):7209-7230

58. Zecca L, Mesonero JE, Stutz A, Poiree JC, Giudicelli J, Cursio R, Gloor SM, Semenza G (1998) Intestinal lactase-phlorizin hydrolase (LPH): the two catalytic sites; the role of the pancreas in pro-LPH maturation. FEBS Lett 435(2-3):225-228

59. Fernandez P, Cañada FJ, Jiménez-Barbero J, Martín-Lomas M (1995) Substrate specificity of small-intestinal lactase: study of the steric effects and hydrogen bonds involved in enzymesubstrate interaction. Carbohyd Res 271(1):31-42. https://doi. org/10.1016/0008-6215(95)00034-Q

60. Colombo V, Lorenz-Meyer H, Semenza G (1973) Small intestinal phlorizin hydrolase: the " $\beta$-glycosidase complex". BBA Enzymol 327(2):412-424. https://doi.org/10.1016/0005-2744(73)90425-7

61. Semenza G, Curtius HC, Raunhardt O, Hore P, Muller M (1969) Configurations at anomeric carbon of reaction products of some digestive carbohydrates. Carbohyd Res 10(3):417. https://doi. org/10.1016/s0008-6215(00)80902-7

62. Leese HJ, Semenza G (1973) On the identity between the small intestinal enzymes phlorizin hydrolase and glycosylceramidase. J Biol Chem 248(23):8170-8173

63. Wacker H, Keller P, Falchetto R, Legler G, Semenza G (1992) Location of the two catalytic sites in intestinal lactase-phlorizin hydrolase. Comparison with sucrase-isomaltase and with other glycosidases, the membrane anchor of lactase-phlorizin hydrolase. J Biol Chem 267(26): 18744-18752

64. Rivera-Sagredo A, CaÑAda FJ, Nieto O, Jimenez-Barbero J, Martin-Lomas M (1992) Substrate specificity of smallintestinal lactase. Eur J Biochem 209(1):415-422. https://doi. org/10.1111/j.1432-1033.1992.tb17304.X

65. Skovbjerg H, Noren O, Sjostrom H, Danielsen EM, Enevoldsen BS (1982) Further characterization of intestinal lactase/phlorizin hydrolase. Biochim Biophys Acta 707(1):89-97

66. Bock K, Adelhorst K (1990) Derivatives of methyl beta-lactoside as substrates for and inhibitors of beta-D-galactosidase from $E$. coli. Carbohyd Res 202:131-149. https://doi.org/10.1016/00086215(90)84076-7

67. Day AJ, Canada FJ, Diaz JC, Kroon PA, McLauchlan R, Faulds CB, Plumb GW, Morgan MR, Williamson G (2000) Dietary flavonoid and isoflavone glycosides are hydrolysed by the lactase site of lactase phlorizin hydrolase. FEBS Lett 468(2-3):166-170

68. Nemeth K, Plumb GW, Berrin JG, Juge N, Jacob R, Naim HY, Williamson G, Swallow DM, Kroon PA (2003) Deglycosylation by small intestinal epithelial cell beta-glucosidases is a critical step in the absorption and metabolism of dietary flavonoid glycosides in humans. Eur J Nutr 42(1):29-42. https://doi.org/10.1007/ s00394-003-0397-3

69. Chen Z, Zheng S, Li L, Jiang H (2014) Metabolism of flavonoids in human: a comprehensive review. Curr Drug Metab 15(1):48-61

70. Berrin JG, McLauchlan WR, Needs P, Williamson G, Puigserver A, Kroon PA, Juge N (2002) Functional expression of human liver cytosolic beta-glucosidase in Pichia pastoris. Insights into its role in the metabolism of dietary glucosides. Eur J Biochem 269(1):249-258

71. Daniels LB, Coyle PJ, Chiao YB, Glew RH, Labow RS (1981) Purification and characterization of a cytosolic broad specificity beta-glucosidase from human liver. J Biol Chem 256(24):13004-13013

72. Noguchi J, Hayashi Y, Baba Y, Okino N, Kimura M, Ito M, Kakuta Y (2008) Crystal structure of the covalent intermediate of human cytosolic $\beta$-glucosidase. Biochem Bioph Res Commun 374(3):549-552. https://doi.org/10.1016/j.bbrc.2008.07.089

73. Owada M, Sakiyama T, Kitagawa T (1977) Neuropathic Gaucher's disease with normal 4-methyiumbelliferyl- $\beta$-glucosidase activity in the liver. Pediatr Res 11(5):641-646. https://doi. org/10.1203/00006450-197705000-00004

74. Beutler E, Beutler L, West C (2004) Mutations in the gene encoding cytosolic $\beta$-glucosidase in Gaucher disease. J Lab Clin Med 144(2):65-68. https://doi.org/10.1016/j.lab.2004.03.013

75. Dekker N, Voorn-Brouwer T, Verhoek M, Wennekes T, Narayan RS, Speijer D, Hollak CEM, Overkleeft HS, Boot RG, Aerts JMFG (2011) The cytosolic $\beta$-glucosidase GBA3 does not influence type 1 Gaucher disease manifestation. Blood Cells Mol Dis 46(1):19-26. https://doi.org/10.1016/j.bcmd.2010.07.009

76. Tribolo S, Berrin JG, Kroon PA, Czjzek M, Juge N (2007) The crystal structure of human cytosolic beta-glucosidase unravels the substrate aglycone specificity of a family 1 glycoside hydrolase. J Mol Biol 370(5):964-975. https://doi.org/10.1016/j. jmb.2007.05.034

77. Lovering AL, Lee SS, Kim YW, Withers SG, Strynadka NC (2005) Mechanistic and structural analysis of a family 31 alphaglycosidase and its glycosyl-enzyme intermediate. J Biol Chem 280(3):2105-2115. https://doi.org/10.1074/jbc.M410468200

78. Berrin J-G, Czjzek M, Kroon PA, McLauchlan WR, Puigserver A, Williamson G, Juge N (2003) Substrate (aglycone) specificity of human cytosolic beta-glucosidase. Biochem J 373(Pt 1):4148. https://doi.org/10.1042/BJ20021876 
79. Kempton JB, Withers SG (1992) Mechanism of Agrobacterium. beta.-glucosidase: kinetic studies. Biochemistry 31(41):99619969. https://doi.org/10.1021/bi00156a015

80. Namchuk MN, Withers SG (1995) Mechanism of Agrobacterium. Beta.-glucosidase: kinetic analysis of the role of noncovalent enzyme/substrate interactions. Biochemistry 34(49):1619416202. https://doi.org/10.1021/bi00049a035

81. Cheeseman C (2008) GLUT7: a new intestinal facilitated hexose transporter. Am J Physiol Endocrinol Metab 295(2):E238-E241. https://doi.org/10.1152/ajpendo.90394.2008

82. Caulfield MJ, Munroe PB, O'Neill D, Witkowska K, Charchar FJ, Doblado M, Evans S, Eyheramendy S, Onipinla A, Howard P, Shaw-Hawkins S, Dobson RJ, Wallace C, Newhouse SJ, Brown M, Connell JM, Dominiczak A, Farrall M, Lathrop GM, Samani NJ, Kumari M, Marmot M, Brunner E, Chambers J, Elliott P, Kooner J, Laan M, Org E, Veldre G, Viigimaa M, Cappuccio FP, Ji C, Iacone R, Strazzullo P, Moley KH, Cheeseman C (2008) SLC2A9 is a high-capacity urate transporter in humans. PLoS Med 5(10):e197. https://doi.org/10.1371/journal.pmed.0050197

83. Rogers S, Macheda ML, Docherty SE, Carty MD, Henderson MA, Soeller WC, Gibbs EM, James DE, Best JD (2002) Identification of a novel glucose transporter-like protein-GLUT-12. Am J Physiol Endocrinol Metab 282(3):E733-E738. https://doi. org/10.1152/ajpendo.2002.282.3.E733

84. Ebert K, Ludwig M, Geillinger KE, Schoberth GC, Essenwanger J, Stolz J, Daniel H, Witt H (2017) Reassessment of GLUT7 and GLUT9 as putative fructose and glucose transporters. J Membrane Biol 250(2):171-182. https://doi.org/10.1007/s0023 2-016-9945-7

85. Pujol-Giménez J, Pérez A, Reyes AM, Loo DDF, Lostao MP (2015) Functional characterization of the human facilitative glucose transporter 12 (GLUT12) by electrophysiological methods. Am J Physiol Cell Physiol 308(12):C1008-C1022. https://doi. org/10.1152/ajpcell.00343.2014

86. Röder PV, Geillinger KE, Zietek TS, Thorens B, Koepsell H, Daniel H (2014) The role of SGLT1 and GLUT2 in intestinal glucose transport and sensing. PLoS ONE 9(2):e89977. https:// doi.org/10.1371/journal.pone.0089977

87. Hediger MA, Coady MJ, Ikeda TS, Wright EM (1987) Expression cloning and cDNA sequencing of the $\mathrm{Na} / \mathrm{glu}-$ cose co-transporter. Nature 330(6146):379-381. https://doi. org/10.1038/330379a0

88. Hirayama BA, Lostao MP, Panayotova-Heiermann M, Loo DD, Turk E, Wright EM (1996) Kinetic and specificity differences between rat, human, and rabbit $\mathrm{Na}+$-glucose cotransporters (SGLT-1). Am J Physiol 270(6):G919-G926. https://doi. org/10.1152/ajpgi.1996.270.6.G919

89. Erokhova L, Horner A, Ollinger N, Siligan C, Pohl P (2016) The sodium glucose cotransporter SGLT1 is an extremely efficient facilitator of passive water transport. J Biol Chem 291(18):9712_ 9720. https://doi.org/10.1074/jbc.M115.706986

90. Turk E, Zabel B, Mundlos S, Dyer J, Wright EM (1991) Glucose/galactose malabsorption caused by a defect in the $\mathrm{Na}+/$ glucose cotransporter. Nature 350(6316):354-356. https://doi. org/10.1038/350354a0

91. Wright EM, Ghezzi C, Loo DDF (2017) Novel and unexpected functions of SGLTs. Physiology 32(6):435-443. https://doi. org/10.1152/physiol.00021.2017

92. Watanabe A, Choe S, Chaptal V, Rosenberg JM, Wright EM, Grabe M, Abramson J (2010) The mechanism of sodium and substrate release from the binding pocket of vSGLT. Nature 468(7326):988-991. https://www.nature.com/nature/journal/ v468/n7326/abs/nature09580.html\#supplementary-information

93. Wright EM, Loo DD, Hirayama BA (2011) Biology of human sodium glucose transporters. Physiol Rev 91(2):733-794
94. Sala-Rabanal M, Hirayama BA, Loo DDF, Chaptal V, Abramson J, Wright EM (2012) Bridging the gap between structure and kinetics of human SGLT1. Am J Physiol Cell Physiol 302(9):C1293-C1305. https://doi.org/10.1152/ajpcell.00397 .2011

95. Sasseville LJ, Morin M, Coady MJ, Blunck R, Lapointe J-Y (2016) The human sodium-glucose cotransporter (hSGLT1) is a disulfide-bridged homodimer with a re-entrant C-terminal loop. PLoS ONE 11(5):e0154589. https://doi.org/10.1371/journ al.pone. 0154589

96. Loo DDF, Jiang X, Gorraitz E, Hirayama BA, Wright EM (2013) Functional identification and characterization of sodium binding sites in Na symporters. Proc Natl Acad Sci USA 110(47):E4557E4566. https://doi.org/10.1073/pnas.1319218110

97. Díez-Sampedro A, Lostao MP, Wright EM, Hirayama BA (2000) Glycoside binding and translocation in $\mathrm{Na}+$-dependent glucose cotransporters: comparison of SGLT1 and SGLT3. J Membrane Biol 176(2):111-117. https://doi.org/10.1007/s00232001081

98. Hummel CS, Lu C, Loo DDF, Hirayama BA, Voss AA, Wright EM (2011) Glucose transport by human renal Na+/d-glucose cotransporters SGLT1 and SGLT2. Am J Physiol Cell Physiol 300(1):C14-C21. https://doi.org/10.1152/ajpcell.00388.2010

99. Hirayama BA, Loo DDF, Díez-Sampedro A, Leung DW, Meinild A-K, Lai-Bing M, Turk E, Wright EM (2007) Sodium-dependent reorganization of the sugar-binding site of SGLT1. Biochemistry 46(46):13391-13406. https://doi.org/10.1021/bi701562k

100. Voss AA, Díez-Sampedro A, Hirayama BA, Loo DDF, Wright EM (2007) Imino sugars are potent agonists of the human glucose sensor SGLT3. Mol Pharmacol 71(2):628-634. https://doi. org/10.1124/mol.106.030288

101. Tazawa S, Yamato T, Fujikura H, Hiratochi M, Itoh F, Tomae M, Takemura Y, Maruyama H, Sugiyama T, Wakamatsu A, Isogai T, Isaji M (2005) SLC5A9/SGLT4, a new Na+-dependent glucose transporter, is an essential transporter for mannose, 1,5-anhydroD-glucitol, and fructose. Life Sci 76(9):1039-1050. https://doi. org/10.1016/j.lfs.2004.10.016

102. Hager K, Hazama A, Kwon HM, Loo DDF, Handler JS, Wright EM (1995) Kinetics and specificity of the renal Na+/myo-inositol cotransporter expressed in Xenopus Oocytes. J Membrane Biol 143(2):103-113. https://doi.org/10.1007/BF00234656

103. Diez-Sampedro A, Lostao M, Wright E, Hirayama B (2000) Glycoside binding and translocation in Na+-dependent glucose cotransporters: comparison of SGLT1 and SGLT3. J Membrane Biol 176(2):111-117

104. Kayano T, Burant CF, Fukumoto H, Gould GW, Fan YS, Eddy RL, Byers MG, Shows TB, Seino S, Bell GI (1990) J Biol Chem 265(22):13276-13282

105. Hirayama BA, Loo DD, Wright EM (1994) Protons drive sugar transport through the Na+/glucose cotransporter (SGLT1). J Biol Chem 269(34):21407-21410

106. Marriott BP, Cole N, Lee E (1235S) National estimates of dietary fructose intake increased from 1977 to 2004 in the United States. J Nutr 139(6):1228S-1235S. https://doi.org/10.3945/ jn.108.098277

107. Patel C, Douard V, Yu S, Gao N, Ferraris RP (2015) Transport, metabolism, and endosomal trafficking-dependent regulation of intestinal fructose absorption. FASEB J 29(9):4046-4058. https ://doi.org/10.1096/fj.15-272195

108. Duro D, Rising R, Cedillo M, Lifshitz F (2002) Association between infantile colic and carbohydrate malabsorption from fruit juices in infancy. Pediatrics 109(5):797-805. https://doi. org/10.1542/peds.109.5.797

109. Wilder-Smith CH, Li X, Ho SS, Leong SM, Wong RK, Koay ES, Ferraris RP (2014) Fructose transporters GLUT5 and GLUT2 expression in adult patients with fructose intolerance. J Physiol 2(1):14-21. https://doi.org/10.1177/2050640613505279 
110. Giroix M-H, Jijakli H, Courtois P, Zhang Y, Sener A, Malaisse WJ (2006) Fructokinase activity in rat liver, ileum, parotid gland, pancreas, pancreatic islet, B and non-B islet cell homogenates. Int J Mol Med 17(3):517-522

111. Stein WD (1972) The mechanism of sugar transfer across erythrocyte membranes. Ann NY Acad Sci 195(1):412-428. https:// doi.org/10.1111/j.1749-6632.1972.tb54823.x

112. Nomura N, Verdon G, Kang HJ, Shimamura T, Nomura Y, Sonoda Y, Hussien SA, Qureshi AA, Coincon M, Sato Y, Abe H, Nakada-Nakura Y, Hino T, Arakawa T, Kusano-Arai O, Iwanari H, Murata T, Kobayashi T, Hamakubo T, Kasahara M, Iwata S, Drew D (2015) Structure and mechanism of the mammalian fructose transporter GLUT5. Nature 526(7573):397-401. https ://doi.org/10.1038/nature14909

113. Tatibouët A, Yang J, Morin C, Holman GD (2000) Synthesis and evaluation of fructose analogues as inhibitors of the d-fructose transporter GLUT5. Bioorgan Med Chem 8(7):1825-1833. https ://doi.org/10.1016/S0968-0896(00)00108-5

114. Tatibouët A, Lefoix M, Nadolny J, Martin OR, Rollin P, Yang J, Holman GD (2001) d-Fructose-1-sorbose interconversions. Access to 5-thio-d-fructose and interaction with the d-fructose transporter, GLUT5. Carbohyd Res 333(4):327-334. https:// doi.org/10.1016/S0008-6215(01)00153-7

115. Yang J, Dowden J, Tatibouët A, Hatanaka Y, Holman GD (2002) Development of high-affinity ligands and photoaffinity labels for the d-fructose transporter GLUT5. Biochem J 367(2):533-539. https://doi.org/10.1042/bj20020843

116. Girniene J, Tatibouët A, Sackus A, Yang J, Holman GD, Rollin $P$ (2003) Inhibition of the d-fructose transporter protein GLUT5 by fused-ring glyco-1,3-oxazolidin-2-thiones and -oxazolidin-2-ones. Carbohyd Res 338(8):711-719. https:// doi.org/10.1016/S0008-6215(03)00007-7

117. Inukai K, Katagiri H, Takata K, Asano T, Anai M, Ishihara H, Nakazaki M, Kikuchi M, Yazaki Y, Oka Y (1995) Characterization of rat GLUT5 and functional analysis of chimeric proteins of GLUT1 glucose transporter and GLUT5 fructose transporter. Endocrinology 136(11):4850-4857. https://doi. org/10.1210/endo.136.11.7588216

118. Kishida K, Martinez G, Iida T, Yamada T, Ferraris RP, Toyoda Y (2019) d-Allulose is a substrate of glucose transporter type 5 (GLUT5) in the small intestine. Food Chem 277:604-608. https://doi.org/10.1016/j.foodchem.2018.11.003

119. Hishiike T, Ogawa M, Hayakawa S, Nakajima D, O'Charoen S, Ooshima H, Sun Y (2013) Transepithelial transports of rare sugar D-psicose in human intestine. J Agr Food Chem 61(30):7381-7386. https://doi.org/10.1021/jf401449m

120. Haradahira T, Tanaka A, Maeda M, Kanazawa Y, Ichiya Y-I, Masuda K (1995) Radiosynthesis, rodent biodistribution, and metabolism of 1-deoxy-1-[18F]fluoro-d-fructose. Nucl Med Biol 22(6):719-725. https://doi.org/10.1016/09698051(95)00018-S

121. Kumar Kondapi VP, Soueidan O-M, Cheeseman CI, West FG (2017) Tunable GLUT-hexose binding and transport via modulation of hexose C-3 hydrogen-bonding capabilities. Chem Eur J 23(33):8073-8081. https://doi.org/10.1002/chem.201701329

122. Trayner BJ, Grant TN, West FG, Cheeseman CI (2009) Synthesis and characterization of 6-deoxy-6-fluoro-d-fructose as a potential compound for imaging breast cancer with PET. Bioorgan Med Chem 17(15):5488-5495. https://doi.org/10.1016/j. bmc.2009.06.034

123. Niu B, Wen X, Jia Z, Wu X, Guo W, Sun H (2013) Synthesis and preliminary evaluation of 1-[18F]Fluoro-1-deoxy-2,5-anhydroD-mannitol as a PET radiotracer for breast cancer imaging. Chin J Chem 31(9):1159-1163. https://doi.org/10.1002/cjoc.20130 0489
124. Soueidan O-M, Trayner BJ, Grant TN, Henderson JR, Wuest F, West FG, Cheeseman CI (2015) New fluorinated fructose analogs as selective probes of the hexose transporter protein GLUT5. Org Biomol Chem 13(23):6511-6521. https://doi.org/10.1039/ C5OB00314H

125. Levi J, Cheng Z, Gheysens O, Patel M, Chan CT, Wang Y, Namavari M, Gambhir SS (2007) Fluorescent fructose derivatives for imaging breast cancer cells. Bioconjugate Chem 18(3):628-634. https://doi.org/10.1021/bc060184s

126. Tanasova M, Plutschack M, Muroski ME, Sturla SJ, Strouse GF, McQuade DT (2013) Fluorescent THF-based fructose analogue exhibits fructose-dependent uptake. ChemBioChem 14(10):1263-1270. https://doi.org/10.1002/cbic.201300164

127. Soueidan O-M, Scully TW, Kaur J, Panigrahi R, Belovodskiy A, Do V, Matier CD, Lemieux MJ, Wuest F, Cheeseman C, West FG (2017) Fluorescent hexose conjugates establish stringent stereochemical requirement by GLUT5 for recognition and transport of monosaccharides. ACS Chem Biol 12(4):1087-1094. https:// doi.org/10.1021/acschembio.6b01101

128. Kannan S, Begoyan VV, Fedie JR, Xia S, Weseliński ŁJ, Tanasova M, Rao S (2018) Metabolism-driven high-throughput cancer identification with GLUT5-specific molecular probes. Biosensors $8(2): 39$

129. Wuest M, Trayner BJ, Grant TN, Jans H-S, Mercer JR, Murray D, West FG, McEwan AJB, Wuest F, Cheeseman CI (2011) Radiopharmacological evaluation of 6-deoxy-6-[18F]fluoro-d-fructose as a radiotracer for PET imaging of GLUT5 in breast cancer. Nucl Med Biol 38(4):461-475. https://doi.org/10.1016/j.nucme dbio.2010.11.004

130. Wuest M, Hamann I, Bouvet V, Glubrecht D, Marshall A, Trayner B, Soueidan O-M, Krys D, Wagner M, Cheeseman C, West F, Wuest F (2018) Molecular imaging of GLUT1 and GLUT5 in breast cancer: a multitracer positron emission tomography imaging study in mice. Mol Pharmacol 93(2):79-89. https ://doi.org/10.1124/mol.117.110007

131. Elferink H, Geurts K, Jue S, MacCormick S, Veeneman G, Boltje TJ (2019) Synthesis and cellular uptake of carbamoylated mannose derivatives. Carbohyd Res 481:67-71. https://doi. org/10.1016/j.carres.2019.06.008

132. Begoyan VV, Weseliński ŁJ, Xia S, Fedie J, Kannan S, Ferrier A, Rao S, Tanasova M (2018) Multicolor GLUT5-permeable fluorescent probes for fructose transport analysis. Chem Commun 54(31):3855-3858. https://doi.org/10.1039/C7CC09809J

133. Drozdowski LA, Thomson ABR (2006) Intestinal sugar transport. World J Gastroenterol 12(11):1657-1670. https://doi. org/10.3748/wjg.v12.i11.1657

134. Thorens B, Guillam M-T, Beermann F, Burcelin R, Jaquet M (2000) Transgenic reexpression of GLUT1 or GLUT2 in pancreatic $\beta$ cells rescues GLUT2-null mice from early death and restores normal glucose-stimulated insulin secretion. J Biol Chem 275(31):23751-23758. https://doi.org/10.1074/jbc.M0029 08200

135. Stümpel F, Burcelin R, Jungermann K, Thorens B (2001) Normal kinetics of intestinal glucose absorption in the absence of GLUT2: evidence for a transport pathway requiring glucose phosphorylation and transfer into the endoplasmic reticulum. Proc Natl Acad Sci USA 98(20):11330-11335. https://doi. org/10.1073/pnas.211357698

136. Thorens B, Sarkar HK, Kaback HR, Lodish HF (1988) Cloning and functional expression in bacteria of a novel glucose transporter present in liver, intestine, kidney, and $\beta$-pancreatic islet cells. Cell 55(2):281-290. https://doi.org/10.1016/00928674(88)90051-7

137. Fukumoto H, Seino S, Imura H, Seino Y, Eddy RL, Fukushima Y, Byers MG, Shows TB, Bell GI (1988) Sequence, tissue distribution, and chromosomal localization of mRNA encoding a 
human glucose transporter-like protein. Proc Natl Acad Sci USA 85(15):5434-5438. https://doi.org/10.1073/pnas.85.15.5434

138. Cheeseman CI (1993) GLUT2 is the transporter for fructose across the rat intestinal basolateral membrane. Gastroenterology 105(4):1050-1056. https://doi.org/10.5555/uri:pii:0016508593 $90948 \mathrm{C}$

139. Thorens B (2015) GLUT2, glucose sensing and glucose homeostasis. Diabetologia 58(2):221-232. https://doi.org/10.1007/ s00125-014-3451-1

140. German MS (1993) Glucose sensing in pancreatic islet beta cells: the key role of glucokinase and the glycolytic intermediates. Proc Natl Acad Sci USA 90(5):1781-1785. https://doi.org/10.1073/ pnas.90.5.1781

141. Kellett GL, Brot-Laroche E (2005) Apical GLUT2 a major pathway of intestinal sugar absorption. Diabetes 54(10):3056-3062

142. Kellett GL (2001) The facilitated component of intestinal glucose absorption. J Physiol 531(3):585-595

143. Helliwell PA, Richardson M, Affleck J, Kellett GL (2000) Regulation of GLUT5, GLUT2 and intestinal brush-border fructose absorption by the extracellular signal-regulated kinase, p38 mitogen-activated kinase and phosphatidylinositol 3-kinase intracellular signalling pathways: implications for adaptation to diabetes. Biochem J 350(1):163-169. https://doi.org/10.1042/bj3500163

144. Cui X-L, Schlesier AM, Fisher EL, Cerqueira C, Ferraris RP (2005) Fructose-induced increases in neonatal rat intestinal fructose transport involve the PI3-kinase/Akt signaling pathway. Am J Physiol 288(6):G1310-G1320. https://doi.org/10.1152/ajpgi 00550.2004

145. Cui X-L, Soteropoulos P, Tolias P, Ferraris RP (2004) Fructoseresponsive genes in the small intestine of neonatal rats. Physiol Genomics 18(2):206-217. https://doi.org/10.1152/physiolgen omics.00056.2004

146. Corpe CP, Eck P, Wang J, Al-Hasani H, Levine M (2013) Intestinal dehydroascorbic acid (DHA) transport mediated by the facilitative sugar transporters, GLUT2 and GLUT8. J Biol Chem 288(13):9092-9101. https://doi.org/10.1074/jbc.M112.436790

147. Fukumura T, Takei M, Suzuki K (2008) Synthesis and biodistribution of 34mCl-labeled 2-chloro-2-deoxy-d-glucose: a major impurity in [18F]FDG injection. Appl Radiat Isotopes 66(12):1905-1909. https://doi.org/10.1016/j.aprad iso.2008.06.042

148. Schnedl WJ, Ferber S, Johnson JH, Newgard CB (1994) STZ transport and cytotoxicity: specific enhancement in GLUT2expressing cells. Diabetes 43(11):1326-1333. https://doi. org/10.2337/diab.43.11.1326

149. Dilz L-M, Denecke T, Steffen IG, Prasad V, von Weikersthal LF, Pape U-F, Wiedenmann B, Pavel M (2015) Streptozocin/5fluorouracil chemotherapy is associated with durable response in patients with advanced pancreatic neuroendocrine tumours. Eur J Cancer 51(10):1253-1262. https://doi.org/10.1016/j. ejca.2015.04.005

150. Moertel CG, Lefkopoulo M, Lipsitz S, Hahn RG, Klaassen D (1992) Streptozocin-doxorubicin, streptozocin-fluorouracil, or chlorozotocin in the treatment of advanced islet-cell carcinoma. New Eng J Med 326(8):519-523. https://doi.org/10.1056/nejm1 99202203260804

151. Bhattacherjee A, Hrynets Y, Betti M (2017) Transport of the glucosamine-derived browning product fructosazine (Polyhydroxyalkylpyrazine) across the human intestinal caco- 2 cell monolayer: role of the hexose transporters. J Agr Food Chem 65(23):4642-4650. https://doi.org/10.1021/acs.jafc.7b01611

152. Faria A, Pestana D, Azevedo J, Martel F, de Freitas V, Azevedo I, Mateus N, Calhau C (2009) Absorption of anthocyanins through intestinal epithelial cells-putative involvement of GLUT2. Mol Nutr Food Res 53(11):1430-1437. https://doi.org/10.1002/ mnfr.200900007
153. Feng M, Betti M (2017) Both PepT1 and GLUT intestinal transporters are utilized by a novel glycopeptide Pro-HypCONH-GlcN. J Agr Food Chem 65(16):3295-3304. https://doi. org/10.1021/acs.jafc.7b00815

154. Kumar P, Shustov G, Liang H, Khlebnikov V, Zheng W, Yang $\mathrm{X}-\mathrm{H}$, Cheeseman C, Wiebe LI (2012) Design, synthesis, and preliminary biological evaluation of 6-o-glucose-azomycin adducts for diagnosis and therapy of hypoxic tumors. J Med Chem 55(13):6033-6046. https://doi.org/10.1021/jm2017336

155. Sala-Rabanal M, Hirayama BA, Ghezzi C, Liu J, Huang S-C, Kepe V, Koepsell H, Yu A, Powell DR, Thorens B, Wright EM, Barrio JR (2016) Revisiting the physiological roles of SGLTs and GLUTs using positron emission tomography in mice. J Physiol 594(15):4425-4438. https://doi.org/10.1113/jp271904

156. Phelps ME (2004) PET: molecular imaging and its biological applications. Springer, Berlin

157. Day AJ, Gee JM, DuPont MS, Johnson IT, Williamson G (2003) Absorption of quercetin-3-glucoside and quercetin-4'-glucoside in the rat small intestine: the role of lactase phlorizin hydrolase and the sodium-dependent glucose transporter. Biochem Pharmacol 65(7):1199-1206. https://doi.org/10.1016/S0006 -2952(03)00039-X

158. Holick M, Ramanathan H (2001) Glycosides and orthoester glycosides of glucocorticoids and uses thereof. US 2001/0041676 A1

159. Holick M, Ramanathan H (2003) Glycuronamides, glycosides and orthoester glycosides of fluoxetine, analogs and uses thereof. WO 2003/073988A2

160. Christian ST, Sundsmo JS (2005) Pharmaceutical dopamine glycoconjugate compositions and methods of their preparation and use. US 2005/0250739 A1

161. Mac Cormic S, Veeneman GH (2019) Method for improving the oral bioavailability of a drug. WO2019121734A1

162. Friend DR, Chang GW (1984) A colon-specific drug-delivery system based on drug glycosides and the glycosidases of colonic bacteria. J Med Chem 27(3):261-266

163. Friend DR, Phillips S, Tozer TN (1991) Colon-specific drug delivery from a glucoside prodrug in the guinea-pig. Efficacy study. J Control Release 15(1):47-54. https://doi. org/10.1016/0168-3659(91)90102-J

164. Nakamura A (2005) Glycoside prodrug of 5- aminosalicylic acid. US 2007/0173461

165. Shull B, Baldwin J, Golopalaswamy R, Haroon Z (2011) Glycosylated acetaminophen pro-drug analogs. US 2012/0022012

166. Curcio A, Sasso O, Melisi D, Nieddu M, La Rana G, Russo R, Gavini E, Boatto G, Abignente E, Calignano A, Rimoli MG (2009) Galactosyl prodrug of ketorolac: synthesis, stability, and pharmacological and pharmacokinetic evaluations. J Med Chem 52(12):3794-3800. https://doi.org/10.1021/jm900051r

167. Zhao X, Tao X, Wei D, Song Q (2006) Pharmacological activity and hydrolysis behavior of novel ibuprofen glucopyranoside conjugates. Eur J Med Chem 41(11):1352-1358. https://doi. org/10.1016/j.ejmech.2006.05.014

168. Di L, Fish PV, Mano T (2012) Bridging solubility between drug discovery and development. Drug Discov Today 17(9):486-495. https://doi.org/10.1016/j.drudis.2011.11.007

169. Williams HD, Trevaskis NL, Charman SA, Shanker RM, Charman WN, Pouton CW, Porter CJH (2013) Strategies to address low drug solubility in discovery and development. Pharmacol Rev 65(1):315-499. https://doi.org/10.1124/pr.112.005660

Publisher's Note Springer Nature remains neutral with regard to jurisdictional claims in published maps and institutional affiliations. 